\title{
Some Implications of Learning for Price Stability*
}

\author{
Stefano Eusepi ${ }^{\dagger} \quad$ Marc P. Giannoni ${ }^{\ddagger} \quad$ Bruce Preston $^{\S}$
}

March 7, 2018

\begin{abstract}
Survey data on expectations of a range of macroeconomic variables exhibit lowfrequency drift. In a New Keynesian model consistent with these empirical properties, optimal policy in general delivers a positive inflation rate in the long run. Two special cases deliver classic outcomes under rational expectations: as the degree of low-frequency variation in beliefs goes to zero, the long-run inflation rate coincides with the inflation bias under optimal discretion; for non-zero low-frequency drift in beliefs, as households become highly patient valuing utility in any period equally, the optimal long-run inflation rate coincides with optimal commitment - price stability is optimal. The optimal statecontingent response to cost-push disturbances similarly reflects properties of optimal discretion and optimal commitment, depending on the degree of low-frequency variation in beliefs. When beliefs exhibit substantial variation in response to short-run forecast errors, optimal policy is closer to commitment.
\end{abstract}

JEL Classifications: E32, D83, D84

Keywords: Optimal monetary policy, Learning dynamics, Price stability

*The authors thank Chris Gibbs, James Hansen and Michael Woodford for useful discussions. The usual caveat applies. The views expressed in the paper are those of the authors and are not necessarily reflective of views at the Federal Reserve Bank of New York, Dallas or the Federal Reserve System. Preston acknowledges reseach support from the Australian Research Council, under the grant FT130101599.

${ }^{\dagger}$ Federal Reserve Bank of New York. E-mail: stefano.eusepi@ny.frb.org.

${ }^{\ddagger}$ Federal Reserve Bank of Dallas. E-mail: marc.giannoni@dal.frb.org.

$\S$ The University of Melbourne. E-mail: bruce.preston@unimelb.edu.au 


\section{Introduction}

If expectations themselves are a source of low-frequency drift in macroeconomic data, then important questions arise about the validity of standard monetary policy advice. While a large literature has emerged evaluating the robustness of rational expectations policy advice to learning dynamics, relatively little attention has been paid to the question of optimal policy design conditional on such belief structures. Important exceptions are Gaspar, Smets and Vestin (2007, 2010), Molnar and Santoro (2013), Eusepi, Giannoni, and Preston (2015) and Mele, Molnar, and Santoro (2015) which explore ways in which optimal policy under learning differs from that under rational expectations. While these papers provide insights on the constraints non-rational belief structures place on monetary policy, they all have in common the implicit assumption that, absent disturbances to the economy, price stability is optimal in the long-run. ${ }^{1}$ Stated differently, conditional expectations of inflation in these analyses converge to price stability as the forecast horizon extends to the indefinite future.

This paper explores whether price stability should be expected to arise as an implication of optimal policy. Building on Molnar and Santoro (2013), a New Keynesian model is adapted to be consistent with low-frequency drift in beliefs identified in macroeconomic data. ${ }^{2}$ The analysis is distinguished from this earlier work by solving for optimal decisions, conditional on the belief structure. We also employ the welfare-theoretic loss function (to a second-order approximation) implied by the microfoundations, which accounts for a distorted steady state arising from monopolistic competition and tax policy. In this environment price stability is, in general, not optimal in the long run, even when a central bank has an inflation target of zero as part of its objectives, and even when fully informed about the nature of agents' expectations formation. Drifting beliefs represent a fundamental constraint on what can be achieved by monetary policy, and optimal policy exhibits an inflation bias of the kind observed under optimal discretion when compared to optimal commitment under rational expectations. In contrast to the inflation bias under discretion, the positive inflation rate under learning is the best a central bank can do - because beliefs are state variables, there is no distinction between commitment and discretion. ${ }^{3}$ However, under some special cases, long-run price

\footnotetext{
${ }^{1}$ Price stability is defined as zero inflation.

${ }^{2}$ There is now a large literature demonstrating that beliefs of the kind studied in this paper not only help explain patterns in standard macroeconomic time series, but also are consistent with a range of survey data measuring expectations. See, inter alia, Carvalho, Eusepi, Moench, and Preston (2015), Adam, Beutel, and Marcet (2017), Branch and Evans (2006), Crump, Eusepi, and Moench (2015), Eusepi, Giannoni, and Preston (2015), Eusepi and Preston (2011, 2017), Kozicki and Tinsley (2001), Milani (2011), Slobydan and Wouters (2012a, 2012b), Malmendier and Nagel (2016), and later discussion.

${ }^{3}$ The equilibrium under discretion and rational expectations can of course be improved by having the
} 
stability will emerge as an optimal outcome under imperfect knowledge.

The mechanism generating a positive optimal inflation rate reflects two competing tensions. As identified by Kydland and Prescott (1977), for given inflation expectations higher household discount factors lead to a deterioration in the short-run output-gap-inflation tradeoff. Exploitation of given expectations generates higher equilibrium inflation rates. However, while learning dynamics imply beliefs are slow-moving state variables, they do adjust over time - indeed, they are consistent with policy in the long run. As beliefs are revised in response to a positive surprise in inflation, permanently higher inflation expectations raise present discounted losses. The central bank internalizes the effects of its policy actions on expectations. For a given sensitivity of beliefs to new information, and, therefore, a given rise in beliefs about long-run inflation, as the discount factor rises, welfare declines - it becomes optimal to lower the inflation rate in the long run. At the same time, the less sensitive are beliefs to new information, the more can beliefs be exploited, because surprise inflation induces smaller adverse shifts in the short-run inflation-output trade-off. This raises the equilibrium long-run inflation rate.

Two special cases are observed when this tension is resolved in favour of one or the other effect, which bounds the optimal rate of inflation, and makes tight connection to rational expectations policy advice. When the size of low-frequency variation in beliefs goes to zero, so that beliefs are almost never revised, the optimal inflation rate coincides with optimal discretion; alternatively, with low-frequency variation in beliefs and when households are highly patient, valuing utility in any period almost equally, then price stability obtains giving the optimal commitment solution. As such, a principle contribution of this work is to make perspicuous connections across optimal policy outcomes under alternative belief structures in the canonical New Keynesian model.

These insights continue to apply to the optimal state-contingent response to disturbances under learning. We study optimal policy in response to cost-push shocks, which deliver a policy trade-off even in the simple New Keynesian framework. Similarly to the steady-state analysis, when low-frequency drift in beliefs is negligible, the stabilization bias in response to shocks coincides with the predictions of optimal discretion. Indeed, the optimal policy problem is formally equivalent to optimal discretion in the limiting case of a zero gain coefficient. Conversely, when long-run inflation expectations exhibit greater sensitivity to short-run forecast errors (i.e. a larger constant gain), and are therefore 'poorly anchored', it becomes optimal to induce some overshooting in the response of inflation to cost-push shocks. This central bank commit. 
property mimics the history-dependence featured by the optimal policy under commitment, which stabilizes the price level to a greater degree than under optimal discretion.

A further contribution concerns recent proposals to raise the Federal Reserve's inflation target from 2 percent, to some higher rate. Blanchard, Dell'Ariccia, and Mauro (2010), Ball (2013) and Krugman (2014) all argue a higher inflation target would lower the potential output costs arising from the zero bound on nominal interest rates. However, Ascari, Phaneuf, and Sims (2015) and Coibion, Gorodnichenko, and Wieland (2012) demonstrate in structural New Keynesian models, that the optimal rate of inflation is not much greater than zero. A range of frictions, such as staggered pricing and wage-contracting, deliver significant welfare costs for non-zero rates of inflation, that more than offset the gains from being constrained by the zero lower bound on interest rates less frequently. The current paper suggests beliefs themselves may be a constraint on policy, under which a positive rate of inflation is optimal. The baseline calibration of our model indicates that relative to rational expectations, drifting beliefs might warrant up to a 2 percent annual inflation target.

\section{The Model}

This section recapitulates a simple New Keynesian model presented in Eusepi and Preston (2016), which is valid for arbitrary beliefs. A range of assumptions, which are without loss of generality, are made for expositional simplicity, and give focus to long-run outcomes. Further details on the microfoundations can be found in Woodford (2003).

A continuum of households $i$ on the unit interval maximize utility

$$
\hat{E}_{t}^{i} \sum_{T=t}^{\infty} \bar{C}_{T} \beta^{T-t}\left[\ln c_{T}(i)-\chi n_{T}(i)\right]
$$

where $0<\beta<1$ and $\chi>0$, by choice of sequences for consumption, $c_{t}(i)$, and labor supply, $n_{t}(i)$, subject to the flow budget constraint

$$
c_{t}(i)+b_{t}(i) \leq\left(1+i_{t}\right) \pi_{t}^{-1} b_{t-1}(i)+W_{t} n_{t}(i) / P_{t}+\Gamma_{t}(i)
$$

and the No-Ponzi condition

$$
\lim _{T \rightarrow \infty} \hat{E}_{t}^{i}\left(\prod_{s=0}^{T-t}\left(1+i_{t+s}\right) \pi_{t+s}^{-1}\right)^{-1} B_{T}(i) \geq 0 .
$$

The variable $b_{t}(i) \equiv B_{t}(i) / P_{t}$ denotes real bond holdings (which in equilibrium are in zero net supply), $i_{t}$ the nominal interest rate, $\pi_{t} \equiv P_{t} / P_{t-1}$ the inflation rate, $W_{t}$ is the hourly 
wage, $\Gamma_{t}(i)$ dividends from equity holdings of firms and $\bar{C}_{T}$ exogenous preference shifter. The operator $\hat{E}_{t}^{i}$ denotes agents' subjective expectations, which might differ from rational expectations. The latter is defined by the operator $\mathbb{E}_{t}$.

A continuum of monopolistically competitive firms maximize profits

$$
\hat{E}_{t}^{j} \sum_{T=t}^{\infty} \alpha^{T-t} Q_{t, T}\left[p_{t}(j) y_{T}(j)-W_{T} n_{T}(j)\right]
$$

by choice of $p_{t}(j)$ subject to the production technology and demand function $y_{T}(j)=n_{T}(j)=$ $\left(p_{t}(j) / P_{T}\right)^{-\theta} Y_{T}$ for all $T \geq t$, with the elasticity of demand across differentiated goods satisfying $\theta>1$; and exogenous probability $0<\alpha<1$ of not being able to reset their price in any subsequent period. When setting prices in period $t$, firms are assumed to value future streams of income at the marginal value of aggregate income in terms of the marginal value of an additional unit of aggregate income today giving the stochastic discount factor $Q_{t, T}=\beta^{T-t}\left(P_{t} Y_{t}\right) /\left(P_{T} Y_{T}\right)$.

In a symmetric equilibrium $c_{t}(i)=c_{t}=w_{t} \equiv W_{t} / P_{t}=n_{t}=Y_{t}$ for all $i, b_{t}(i)=b_{t}(j)$ for all $i, j$, while for all firms changing prices in period $t, p_{t}(i)=p_{t}(j)$. To a first-order log-linear approximation, in the neighborhood of a zero-inflation steady state, individual consumption and pricing can be expressed as

$$
\begin{aligned}
& \hat{c}_{t}(i)=\hat{E}_{t}^{i} \sum_{T=t}^{\infty} \beta^{T-t}\left[(1-\beta) \hat{w}_{T}-\beta\left(\hat{\imath}_{T}-\hat{\pi}_{T+1}-\hat{r}_{T}^{n}\right)\right] \\
& \hat{p}_{t}(j)=E_{t}^{j} \sum_{T=t}^{\infty}(\alpha \beta)^{T-t}\left[(1-\alpha \beta) \hat{w}_{T}+\alpha \beta \hat{\pi}_{T+1}\right]
\end{aligned}
$$

where for any variable $z_{t}, \hat{z}_{t}=\ln \left(z_{t} / \bar{z}\right)$ the $\log$-deviation from steady state $\bar{z}$, with the exceptions $\hat{p}_{t}(j)=\ln \left(p_{t}(j) / P_{t}\right)$, and $\hat{\imath}_{t}=\ln \left[\left(1+i_{t}\right) /(1+\bar{\imath})\right]$. The associated natural rate of interest $\hat{r}_{t}^{n}=\bar{c}_{t}-\hat{E}_{t} \bar{c}_{T+1}$ is determined by exogenous fluctuations in the propensity to consume, $\bar{c}_{t}=\ln \left(\bar{C}_{t} / \bar{C}\right)$, a stationary process. ${ }^{4}$ The caret denoting log deviation from steady state is dropped for the remainder. Aggregating across the continuum of households and firms, and imposing market-clearing conditions, the economy is described by the aggregate demand and supply equations

$$
x_{t}=\hat{E}_{t} \sum_{T=t}^{\infty} \beta^{T-t}\left[(1-\beta) x_{T+1}-\left(i_{T}-\pi_{T+1}-r_{T}^{n}\right)\right]
$$

\footnotetext{
${ }^{4}$ Relation (1) imposes the equilibrium condition of zero net supply of goverment debt.
} 


$$
\pi_{t}=\hat{E}_{t} \sum_{T=t}^{\infty}(\alpha \beta)^{T-t}\left[\kappa x_{T}+(1-\alpha) \beta \pi_{T+1}\right]
$$

where the output gap is defined as

$$
x_{t}=y_{t}-y_{t}^{n}=w_{t}
$$

the difference between output and the natural rate of output, the level of output determined by a flexible price economy: here $y_{t}^{n}=0$. The aggregate demand equation determines the output gap as the discounted expected value of future wages, with the second term capturing variations in the real interest rate, applied in future periods, due to changes in nominal interest rates and goods price inflation. The aggregate supply curve determines inflation as the discounted future sequence of marginal costs and the inflation rate. The slope of the Phillips curve is measured by $\kappa=(1-\alpha \beta)(1-\alpha) / \alpha$. The model is closed with assumptions on policy expectations, which are developed in subsequent sections. ${ }^{5}$

\subsection{Beliefs}

Households have incomplete knowledge about the true structure of the economy. They observe only their own objectives, constraints and realizations of aggregate variables as well as prices that are exogenous to their decision problems and beyond their control. They have no knowledge of either the market mechanisms which determine the equilibrium evolution of aggregate prices and quantities or the prevailing policy regime. To forecast various prices and policy variables exogenous to their decision problem they adopt an econometric model estimated on available historical data.

To give emphasis to long-run outcomes, assume natural-rate shocks are iid. Because the model is purely forward looking under rational expectations, equilibrium implies endogenous variables are linear functions of the natural-rate disturbance, with zero mean in deviations from steady state. Assume then that agents have the following forecasting model

$$
\begin{aligned}
& z_{t}=a_{t}+\varepsilon_{t} \\
& a_{t}=a_{t-1}+v_{t}
\end{aligned}
$$

\footnotetext{
${ }^{5}$ We also assume a cashless economy with no government spending and no government debt. For analyses of fiscal policy under learning dynamics see Eusepi and Preston (2012, 2017). However, including explicitly the fiscal activities of the government does not alter results, at least under the assumption of lump-sum taxation.
} 
where

$$
z_{t}=\left[\begin{array}{c}
\pi_{t} \\
x_{t} \\
i_{t}
\end{array}\right] \text { and } a_{t}=\left[\begin{array}{c}
a_{t}^{\pi} \\
a_{t}^{x} \\
a_{t}^{i}
\end{array}\right]
$$

and $E\left[\varepsilon_{t} \varepsilon_{t}^{\prime}\right]=R$ and $E\left[v_{t} v_{t}^{\prime}\right]=Q$ give the prior beliefs on the variance of iid primitive disturbances, $\varepsilon_{t}$, and innovations to low-frequency drift, $v_{t}$. This unobserved components model implies agents only need to learn the long-run averages of each series. ${ }^{6}$ This is the only source of uncertainty agents face about the true dynamics — therefore called a "shifting endpoint model" by Kozicki and Tinsley (2001). As the prior variance $Q$ goes to zero, the forecasting model converges to rational expectations beliefs.

Beliefs are revised according to a standard Kalman filter recursion. Given emphasis to long-run outcomes, we assume a steady-state Kalman filter, in which agents have priors satisfying

$$
Q=g^{2} R
$$

for a constant gain coefficient $0<g<1$. This implies beliefs evolve according to

$$
a_{t}=a_{t-1}+g\left(z_{t}-a_{t-1}\right) \text {. }
$$

Because $Q$ is in general non-zero, beliefs fail to converge to rational expectations equilibrium in the presence of uncertainty. However, as shown by Evans and Honkapohja (2003), beliefs will be ergodically distributed around the underlying rational expectations equilibrium. Forecasts are then determined as

$$
\hat{E}_{t} z_{T}=a_{t-1}
$$

which, combined with the structural equations, provides the solution to the model — see Sargent (1999) and Eusepi and Preston (2016) for discussion. Note, as is standard in the learning literature, long-run conditional expectations of any variable are revised only in response to surprise movements in that same variable. See Sargent, Williams, and Zha (2006) and Eusepi, Giannoni, and Preston (2015) for more general analyses.

Four remarks are warranted. First, Crump, Eusepi, and Moench (2015) demonstrate a closely related class of beliefs are consistent with the properties of a large range of professional forecasts. ${ }^{7}$ Furthermore, these beliefs will be consistent with any model in which agents

\footnotetext{
${ }^{6}$ This form of learning is often referred to as steady-state learning in the learning literature.

${ }^{7}$ Formally they permit estimates of the long-run conditional mean of any variable to depend on shortrun forecast errors of all variables. The Kalman gain matrix in this case cannot be summarized by a single gain coefficient. While the results of Eusepi, Giannoni, and Preston (2015) make clear such belief structures place constraints on equilibrium dynamics under optimal policy, the simpler case is considered here to obtain analytical results.
} 
deploy, and make decisions based upon, an econometric filter to form inference about the longrun conditional mean of the data. Second, this belief structure delivers analytical tractability, ensuring a linear-quadratic optimal policy problem which can be solved using standard methods. Third, the assumption is less restrictive than might be thought. In fact, the drift term generally imposes the strictest requirements on policy for stability and, more generally, it drives the largest deviations relative to rational expectations predictions. ${ }^{8}$ Moreover, the drift itself has a clean economic interpretation representing time variation in the perceived long-run conditional mean of each variable of interest. In the case of inflation, it reflects uncertainty about a central bank's inflation target. Fourth, for more general specifications of monetary policy the evolution of beliefs may depend upon lagged endogenous variables, such as the output gap under the optimal commitment policy. However, the dynamics of the output gap are mean reverting. Hence, in the long run, the only relevant uncertainty concerns low-frequency drift. The assumed belief structure, therefore, captures the variation of interest for making the conceptual points of the paper.

\section{The Policy Problem}

The central bank seeks to minimize the expected discounted quadratic loss

$$
\mathbb{E}_{0} \sum_{t=0}^{\infty} \beta^{t}\left[\pi_{t}^{2}+\lambda_{x}\left(x_{t}-x^{*}\right)^{2}\right]
$$

where $\lambda_{x} \geq 0$ determines the relative weight placed on inflation stabilization versus output gap stabilization, and $x^{*}$ is the optimal output gap. ${ }^{9}$ The period loss function is derived as a second-order approximation to household utility. The assumption of non-rational expectations does not affect these calculations. The optimal output gap is proportional to the difference between the steady-state efficient and natural rates of output — which here differ due to monopolistic competition. ${ }^{10}$

Assume the central bank has rational expectations and knows the structure of the economy. Assuming rational expectations serves to emphasize the degree to which imperfect knowledge on the part of households and firms constrains what can be achieved - a less sophisticated central bank presumably faces a more difficult control problem.

\footnotetext{
${ }^{8}$ See Bullard and Mitra (2002) and Preston (2005) for examples relating to expectational stability results; and Eusepi and Preston (2011) and Eusepi and Preston (2018) for quantitative results.

${ }^{9}$ Given our assumptions of linear disutility of labour supply, linear production and log utility of consumption $x^{*}=\log \left(Y^{*} / \bar{Y}\right)=(\theta-1) / \theta$ where $Y^{*}$ denotes the efficient level of output, and $\bar{Y}$ the natural rate of output.

${ }^{10}$ See Woodford (2003) for derivations.
} 


\subsection{Rational Expectations Equilibrium}

Under rational expectations the aggregate demand and supply equations can be given the familiar recursive representation

$$
\begin{aligned}
& x_{t}=\mathbb{E}_{t} x_{t+1}-\left(i_{t}-E_{t} \pi_{t+1}-r_{t}^{n}\right) \\
& \pi_{t}=\kappa x_{t}+\beta \mathbb{E}_{t} \pi_{t+1} .
\end{aligned}
$$

The conditions under which relations (3) and (4) are reducible to these expressions are discussed by Preston (2005) and Eusepi and Preston (2016). The central bank seeks to minimize the objective function (5) subject to (6) and (7) by choice of state-contingent sequences $\left\{x_{t}, \pi_{t}, i_{t}\right\}$. The following proposition can be stated.

Proposition 1 Under rational expectations, optimal policy under discretion implies long-run inflation is

$$
\pi^{D}=\lim _{T \rightarrow \infty} \mathbb{E}_{t} \pi_{t+T}=\frac{\kappa \lambda_{x} x^{*}}{\kappa^{2}+\lambda_{x}(1-\beta)} .
$$

Optimal policy under commitment implies long-run inflation is

$$
\pi^{C}=\lim _{T \rightarrow \infty} \mathbb{E}_{t} \pi_{t+T}=0
$$

Proofs for these standard results can be found in Woodford (2003). The proposition establishes the classic inflation-bias first identified by Kydland and Prescott (1977). The bias is larger the greater the weight given output gap stabilization; the larger is the household discount factor; and the larger the slope of the Phillips curve, which in turn is larger the greater the frequency of price adjustment. Under commitment, the welfare loss from staggered price-setting, the model's only friction, is minimized under price stability.

\subsection{Learning Dynamics}

Under learning dynamics feasible inflation and output gap sequences must satisfy the aggregate demand (3) and aggregate supply (4) relations. Evaluating the forecasts in each expression provides

$$
\begin{aligned}
& \pi_{t}=\kappa x_{t}+\kappa \frac{\alpha \beta}{1-\alpha \beta} a_{t-1}^{x}+\frac{(1-\alpha) \beta}{1-\alpha \beta} a_{t-1}^{\pi} \\
& x_{t}=-\left(i_{t}-r_{t}^{n}\right)-\frac{1}{1-\beta}\left(\beta a_{t-1}^{i}-a_{t-1}^{\pi}\right)+a_{t-1}^{x}
\end{aligned}
$$


with beliefs evolving according to

$$
\begin{aligned}
a_{t}^{\pi} & =a_{t-1}^{\pi}+g\left(\pi_{t}-a_{t-1}^{\pi}\right) \\
a_{t}^{x} & =a_{t-1}^{x}+g\left(x_{t}-a_{t-1}^{x}\right) \\
a_{t}^{i} & =a_{t-1}^{i}+g\left(i_{t}-a_{t-1}^{i}\right) .
\end{aligned}
$$

The optimal policy problem is to minimize the loss (5) subject to the five constraints (8)-(12) by choice of sequences $\left\{x_{t}, \pi_{t}, i_{t}, a_{t}^{\pi}, a_{t}^{x}, a_{t}^{i}\right\}$, taking as given initial beliefs $a_{-1}^{\pi}, a_{-1}^{x}$ and $a_{-1}^{i}{ }^{11}$ Eusepi, Giannoni and Preston (2015) emphasize two properties of optimal policy problems under drifting beliefs. First, there is no distinction between discretion and commitment. Beliefs are state variables. Second, the aggregate demand equation is in general a constraint on the optimal choices of the central bank. Because of the interdependence between interest rates and interest-rate beliefs, it will not be true one can always determine from the aggregate demand equation an interest-rate path that is consistent with any choice of sequences for the output gap and inflation rate.

The first-order conditions characterizing optimality are described in the appendix. They constitute a system of linear rational expectations equations in the variables

$$
\left\{x_{t}, \pi_{t}, i_{t}, a_{t}^{\pi}, a_{t}^{x}, a_{t}^{i}, \lambda_{1, t}, \lambda_{2, t}, \lambda_{3, t}, \lambda_{4, t}, \lambda_{5, t}\right\}
$$

where $\lambda_{j, t}$ for $j \in[1,5]$ are Lagrange multipliers attached to each of the five constraints, whose solution has the following general properties.

Proposition 2 If the system composed of the conditions (8)-(12) and the policy problem's first-order conditions admits a bounded solution, then this system has a unique bounded rational expectations equilibrium for all initial conditions $\left\{a_{-1}^{\pi}, a_{-1}^{x}, a_{-1}^{i}\right\}$. The unique steady-state implies

$$
\pi^{L R}=\lim _{T \rightarrow \infty} \mathbb{E}_{t} \pi_{T}=\frac{\lambda_{x} \kappa x^{*}}{\kappa^{2} \Xi+\lambda_{x}(1-\beta)}
$$

and

$$
x^{L R}=\lim _{T \rightarrow \infty} \mathbb{E}_{t} x_{T}=0
$$

where

$$
\Xi=\frac{g \beta+(1-\beta)(1-\alpha \beta)}{g \beta(1-\beta)+(1-\beta)(1-\alpha \beta)} \geq 1
$$

\footnotetext{
${ }^{11}$ We assume agents do not seek to compute the optimal gain, given the policy framework, and that the central bank takes the gain as given. If forecasts were computed using the optimal gain, the policy problem would not longer be linear-quadratic.
} 
The proof, which appeals to results in Giannoni and Woodford (2017), is in the Appendix. The logic of this result implies that regardless of the sources of uncertainty, long-run conditional expectations converge to steady state provided the equilibrium is bounded. For this reason, inclusion of different shocks, and specifically cost-push shocks, or more general specifications of statistical processes for these shocks, has no effect on long-run conditional expectations. And for similar reasons, the results extend to certain models of imperfect central bank knowledge of household and firm beliefs. For example, suppose the central bank actually observes, and makes policy decisions based upon,

$$
\tilde{a}_{t}^{k}=a_{t}^{k}+\varepsilon_{t}^{k} \quad \text { for } \quad k \in\{\pi, x, i\}
$$

rather than $a_{t}^{k}$, where the $\varepsilon_{t}^{k}$ are stationary independent stochastic processes. This can be interpreted as either imperfect observation of household and firm beliefs (because of noisy survey data), or a particular kind of control error in the implementation of optimal policy. In such situations, proposition 2 continues to hold, as does the following corollary to that result. $^{12}$

Corollary 3 The system always admits a bounded solution for $g \in(0,1)$ that satisfy $(i)$ either $g<2(1-\beta)$ or $g>\beta^{-1}-\beta$, and, (ii) in the case $g>\frac{(1-\alpha \beta)\left(\lambda_{x}+\kappa^{2}\right)}{\lambda_{x}(1-\beta)+\kappa^{2}}$, either $g<2(1-\alpha \beta)$ or $g>\left(\beta^{-1}+1\right)(1-\alpha \beta)$.

Again, details are in the appendix. These conditions are met when $\beta \leq 1 / 2$, and generally also when $\beta$ is large enough. For instance, if $\beta=0.99$, the system admits a bounded solution for any $g$ other than in the intervals $[0.0200,0.0201]$ and $[2(1-\alpha \beta), 2.01(1-\alpha \beta)] .{ }^{13}$ When the above conditions are violated, some variables may not be bounded. In particular, while inflation and the output gap remain close to their optimal steady state under optimal policy, the nominal interest tends to fluctuate more and more as $g$ approaches these thresholds.

\subsection{Some Implications}

The steady state of inflation (13) obtained in Proposition 2 shows price stability is in general not optimal under imperfect knowledge. Optimal policy delivers a positive inflation rate, the

\footnotetext{
${ }^{12}$ Formally, for the logic to apply directly, the central bank cannot be aware that it observes a noisy measure of expectations, or is subject to control error. If it did, it should solve a filtering problem to form an estimate of $a_{t}^{k}$ based on observables and the noisy signal, and implement policy accordingly. While the results are likely to apply in the case of iid errors (there is nothing for the central bank to learn in this case), establishing more general results is left for later work.

${ }^{13}$ While the restrictions (i) are necessary for a bounded solution, conditions (ii) are sufficient but not necessary.
} 
magnitude of which depends on all model parameters, so long as the optimal output gap is positive. However, under maintained parametric assumptions the optimal inflation rate is no larger than what obtains under optimal discretion. Long-run inflation is endogenous in the sense that while it is true that a policy maker attempts to have beliefs evolve in a certain way, in equilibrium different beliefs lead to different inflation outcomes — beliefs constrain what can be achieved by monetary policy. Importantly, in the long-run beliefs are consistent with observed outcomes. There are no systematic errors on the part of agents.

Two limiting cases are revealing. Consider beliefs in which the constant gain is in the neighborhood of zero. Then long-run inflation is given by the expression

$$
\lim _{g \rightarrow 0} \pi^{L R}=\frac{\kappa \lambda_{x} x^{*}}{\kappa^{2}+\lambda_{x}(1-\beta)}
$$

which is precisely the inflation bias observed in this model with rational expectations and under optimal policy with discretion. That this occurs follows immediately from the nature of beliefs. With a gain in the neighborhood of zero, beliefs are approximately never revised - monetary policy cannot influence beliefs. The central bank therefore takes expectations as given, exactly as would be the case if firms had rational expectations.

Alternatively, suppose households are very patient, approximately weighting utility in each period equally. Noting that

$$
\lim _{\beta \rightarrow 1} \Xi=\infty
$$

the optimal long-run inflation rate is given by

$$
\lim _{\beta \rightarrow 1} \pi^{L R}=0
$$

Price stability is optimal, and, importantly, the outcome under optimal commitment policy under rational expectations. This establishes an important robustness result. Optimal commitment policies under rational expectations are often criticized on the ground that they rely too heavily on the ability to manage future expectations through announcements. ${ }^{14}$ This result indicates price stability may nonetheless be optimal even when a central bank has no influence over future expectations through announced policy actions, and can only influence beliefs through actions, so long as households have a high degree of patience. We return to this issue when discussing the optimal state-contingent response to disturbances.

\footnotetext{
${ }^{14}$ See Woodford (2010) for one response to this concern.
} 


\subsection{Some Intuition}

To provide intuition, Figure 1 plots long-run inflation as a function of beliefs and household patience. Parametric assumptions are: $\lambda_{x}=\kappa / \theta$ where $\theta$ is the elasticity of demand; $x^{*}=$ $0.05 ; \kappa=0.052 ; \beta=0.99$; and $\alpha=0.80$ — standard values in Woodford (2003). In the case of a gain in the neighborhood of zero, the discretionary inflation bias obtains. As is well understood, as the discount factor of households rises, the short-run trade-off between inflation and the output gap worsens. In equilibrium, the long-run inflation rate increases as the central bank nonetheless attempts to achieve the optimal output gap $x^{*}$.

For positive gains, a second effect operates. As before, an higher discount factor raises equilibrium long-run inflation due to the worsening short-run trade-off between inflation and the output gap. However, the central bank internalizes the effects of policy on the evolution of inflation expectations. Higher inflation leads to higher present discounted losses, exacerbated by greater concern about the future at higher discount factors. This leads to lower desired equilibrium inflation in the long run. This second effect is stronger the larger the gain - i.e. the more sensitive beliefs are to inflation. The limiting case of a perfectly patient household would lead to an infinite loss at any positive rate of inflation. There is no advantage to exploiting expectations in the short-run, making price stability optimal.

Figure 2 plots the optimal long-run inflation rate as a function of the gain for different values of the discount factor. For gains in the neighborhood of zero, the rational expectations average bias is observed, regardless of household patience. As the gain rises, higher discount factors imply greater present discounted losses from exploiting the sluggishness of inflation expectations. It becomes optimal to deliver low long-run equilibrium inflation.

Proposition 4 In general the optimal long-run inflation rate is positive such that

$$
0=\pi^{C} \leq \pi^{L R} \leq \pi^{D}
$$

and satisfies the limit properties

$$
\begin{aligned}
& \lim _{\beta \rightarrow 1} \pi^{L R}=\pi^{C} \\
& \lim _{g \rightarrow 0} \pi^{L R}=\pi^{D} .
\end{aligned}
$$

The proof follows directly from (13) and Proposition 1.

The insights of figure 2 acquire further interest in the light of recent discussion about the optimal inflation rate. Ascari, Phanouf and Sims (2015) and Coibion, Gorodnichenko and Wieland (2011) demonstrate in structural New Keynesian models with rational expectations 


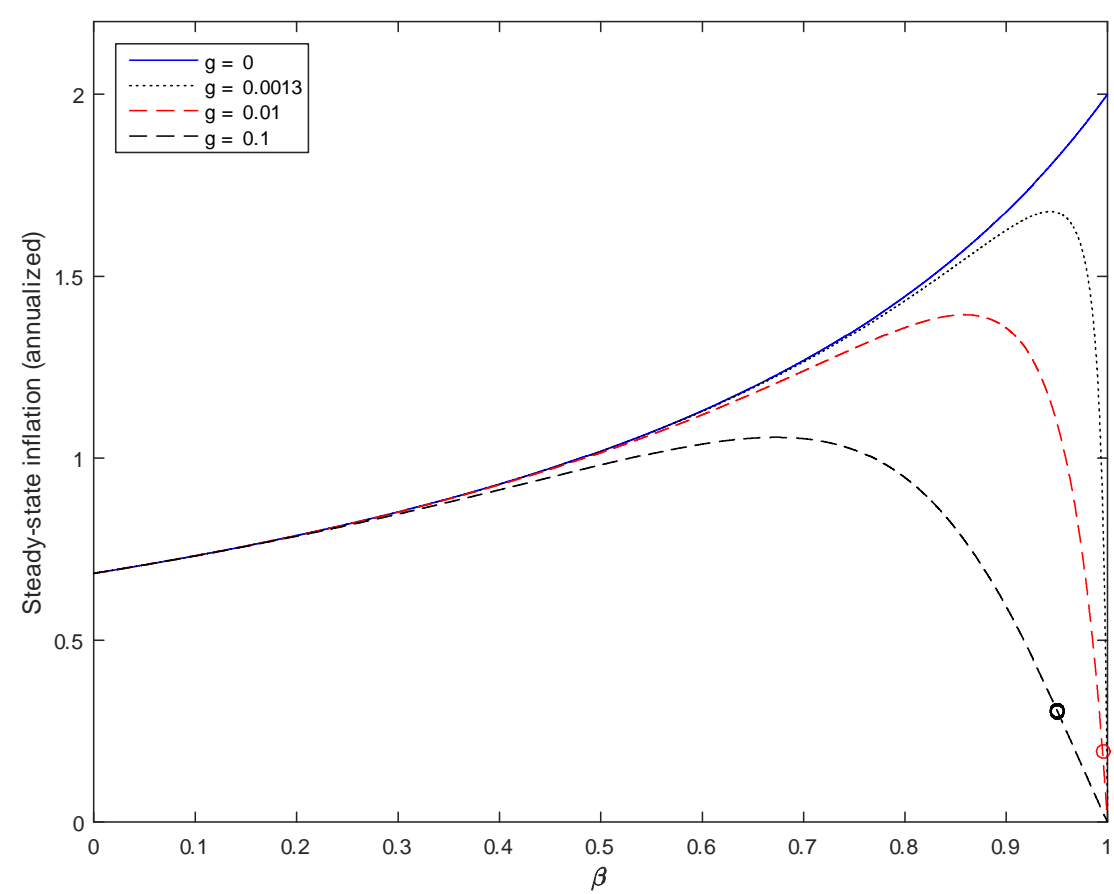

Figure 1: Steady-state inflation as a function of the discount factor for different gains. Circles denote points in the parameter space which fail to satisfy the conditions of proposition 2 .

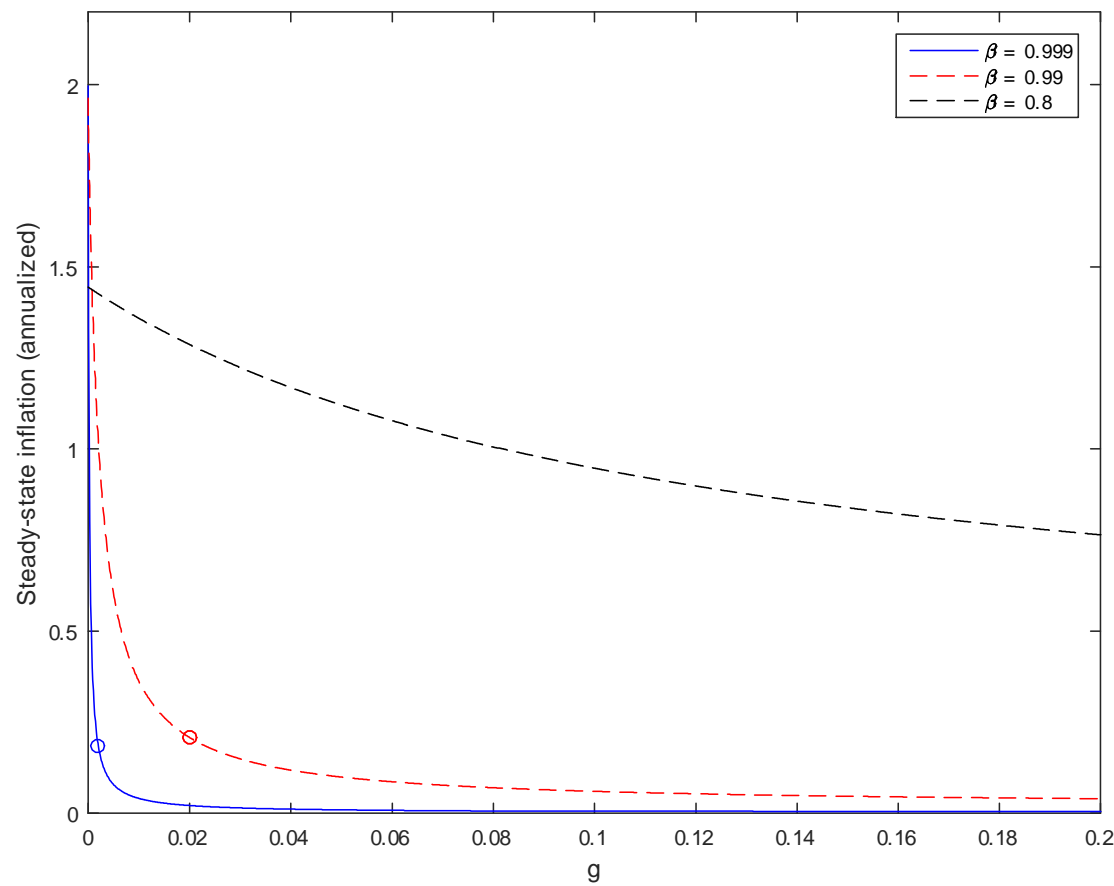

Figure 2: Steady state inflation as functions of the gain for different discount factors. Circles denote points in the parameter space which fail to satisfy the conditions of proposition 2 . 
that the optimal rate of inflation is not much greater than zero. As the average inflation rate rises, various frictions generate costs sufficient to offset the benefits of avoiding the zero lower bound on interest rates. The learning literature adduces evidence for a range of gain coefficients often of the order 0.01 to 0.1 - and occasionally higher values. And Eusepi and Preston (2011) estimate a gain of 0.0013, using a real business cycle model solved under the anticipated utility approach adopted here. Acknowledging this estimate comes from a very different economic environment, for this value the optimal inflation rate ranges from zero to about 2 percent on an annual basis. With $\beta$ equal to 0.99 , the optimal inflation rate becomes quite different from zero, equal to about 1.5 percent. While a serious study of the quantitative relevance of learning dynamics for the optimal inflation rate is beyond the present discussion, this casual empiricism suggests learning might be an important argument in favor of higher inflation targets.

A final observation is warranted. One can interpret the gain as a metric of credibility. In the model agents are attempting to learn, among other things, the long-run inflation objective of the central bank. The smaller the gain, the smaller the drift in beliefs about the long-run inflation target in response to different disturbances. The results indicate that a central bank perceived as more credible would find it optimal to have a higher inflation rate. Exemplifying this interpretation, Carvalho, Eusepi, Moench, and Preston (2015) show, using a model with a state-contingent gain fitted to US data, the 1970s are characterized by a high gain of 0.14, while in the past 20 years the gain has been small and declining to value of about 0.015 in recent years, as the Federal Reserve acquired greater credibility for low and stable inflation: beliefs over this latter period exhibit strong convergence to the central bank's inflation target. Over this time the incentives of the central bank to create, optimally, positive inflation rise with the decline in gain, reflecting increased latitude to respond to economic developments when beliefs are less sensitive to new information.

\subsection{Response to shocks: inflation overshooting}

The literature on optimal policy emphasizes two differences between discretion and commitment equilibria under rational expectations: long-run average outcomes and the statecontingent responses to shocks. This section explores whether the above results on the optimal long-run inflation rate also apply to transitional dynamics. Given the simple belief structure it is immediate the model under learning can never replicate the optimal commitment equilibrium, as the lagged output gap is a state variable under such policy. Because more general belief structures of this kind render the model non-linear, we instead focus on whether op- 
timal policy under learning replicates a key property of optimal commitment equilibria that of history dependence. Unlike the optimal discretion policy, the optimal commitment policy delivers a stationary price level. Disturbances that lower inflation on impact engender policy responses which deliver a period of higher than average inflation to restore the price level to its initial value. Does optimal policy under learning deliver such overshooting and stabilization of the price level?

To explore this possibility, modify the Phillips curve (4) as

$$
\pi_{t}=\hat{E}_{t} \sum_{T=t}^{\infty}(\alpha \beta)^{T-t}\left[\kappa x_{T}+(1-\alpha) \beta \pi_{T+1}+\hat{\mu}_{T}\right]
$$

where $\hat{\mu}_{t}$ measures an i.i.d. cost-push shock driven by fluctuations in firm's demand elasticity. For simplicity, and to focus on inflation expectations, assume the central bank has direct control of the output gap as the instrument of policy. This is equivalent to assuming households have rational expectations. In this case, the aggregate demand equation (3) is no longer a binding constraint on the central bank's optimal policy problem. ${ }^{15}$ The central bank then minimizes the loss, (5), subject to the aggregate supply curve, (14), and beliefs (10) and (11). The first-order conditions to this problem give a linear rational expectations system in the variables

$$
\left\{\pi_{t}, x_{t}, \lambda_{1, t}, \lambda_{2, t}, \lambda_{3, t}\right\}
$$

where the $\lambda_{i, t}$ are the lagrange multipliers on each of the constraints.

Because of the dimension of the system analytical solutions are not available. We therefore compare the impulse responses of inflation (in deviation from steady state) to a negative costpush shock under optimal discretion, optimal commitment and optimal policy with learning under different assumptions about the constant gain. For the transitional dynamics to replicate the insights from optimal long-run policy, we should observe lower gains generate similar predictions to optimal discretion, and larger gains predictions closer to optimal commitment - recall figure 1. Model parameters are fixed at earlier values. We also set $\beta=0.99$, while considering alternative assumptions about the central bank's weight on output gap, $\lambda_{x}$.

Figure 3 displays the impulse response of inflation assuming $\lambda_{x}$ is consistent with households' utility, and the constant gain is small, taking the value $g=0.001$. In this case, as in the steady-state analysis, optimal discretion and optimal policy under learning imply the

\footnotetext{
${ }^{15}$ Eusepi, Giannoni and Preston (2015) show that the response to shocks under more general conditions can be different, as the central bank is confronted with an additional intertemporal trade-off operating through the term structure of interest rates.
} 


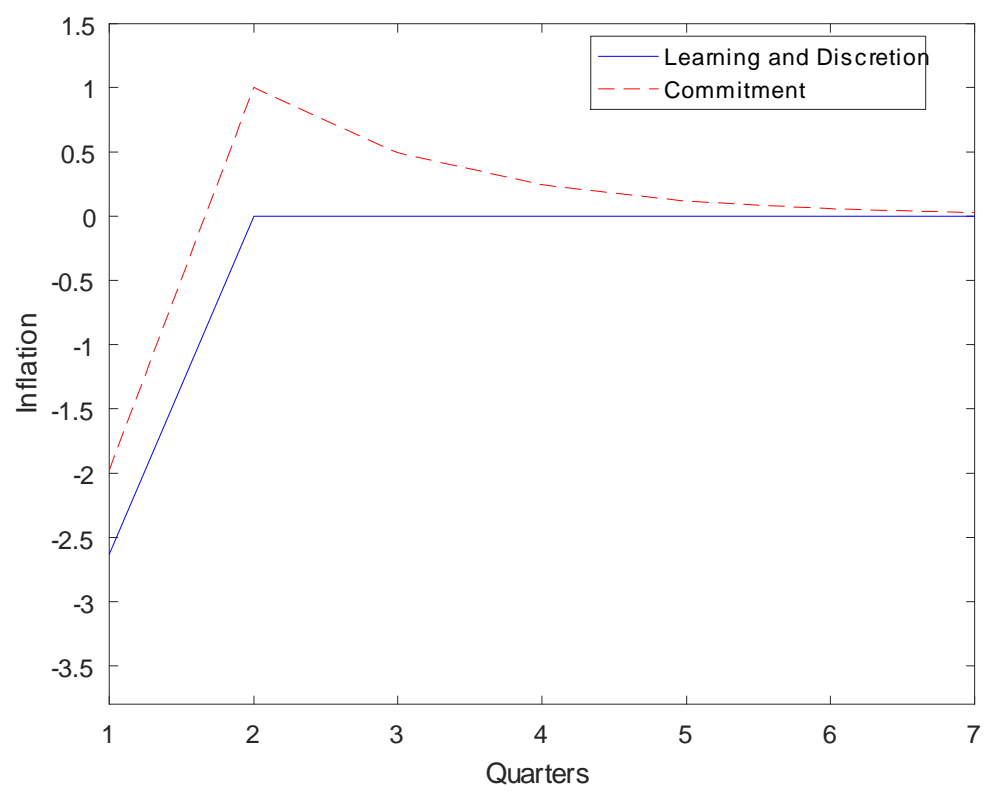

Figure 3: Impulse response to a negative cost-push shock, reducing inflation. The gain is $g=0.001$.

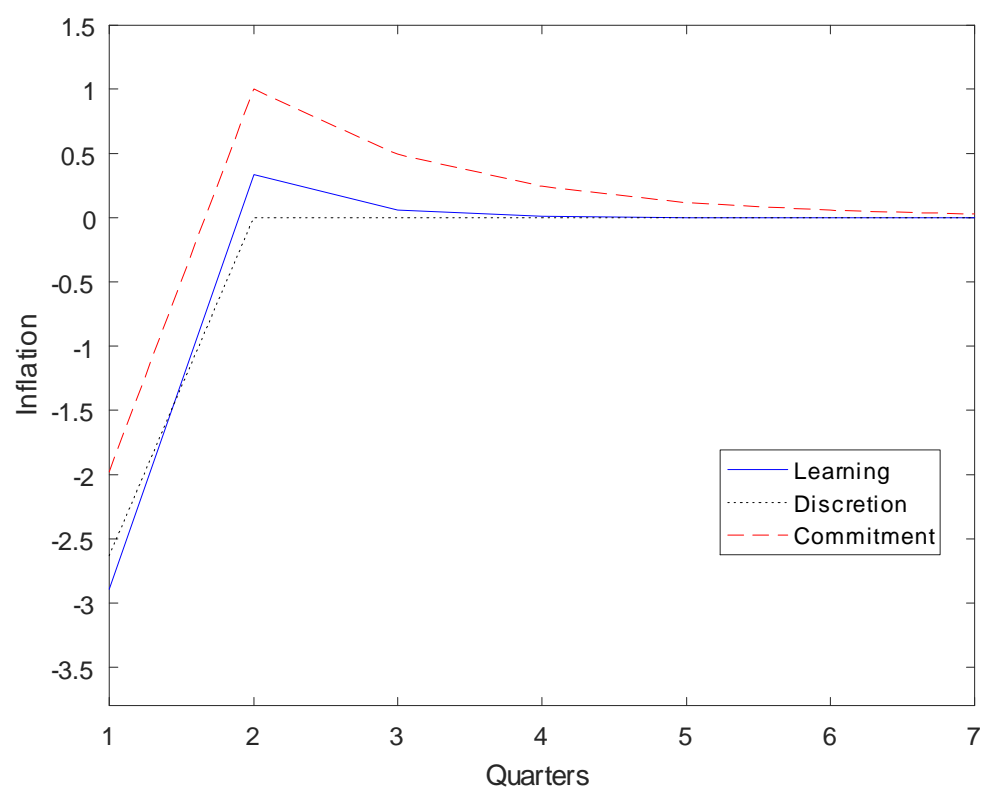

Figure 4: Impulse response to a negative cost-push shock, reducing inflation. The gain is set to $g=0.4$. 


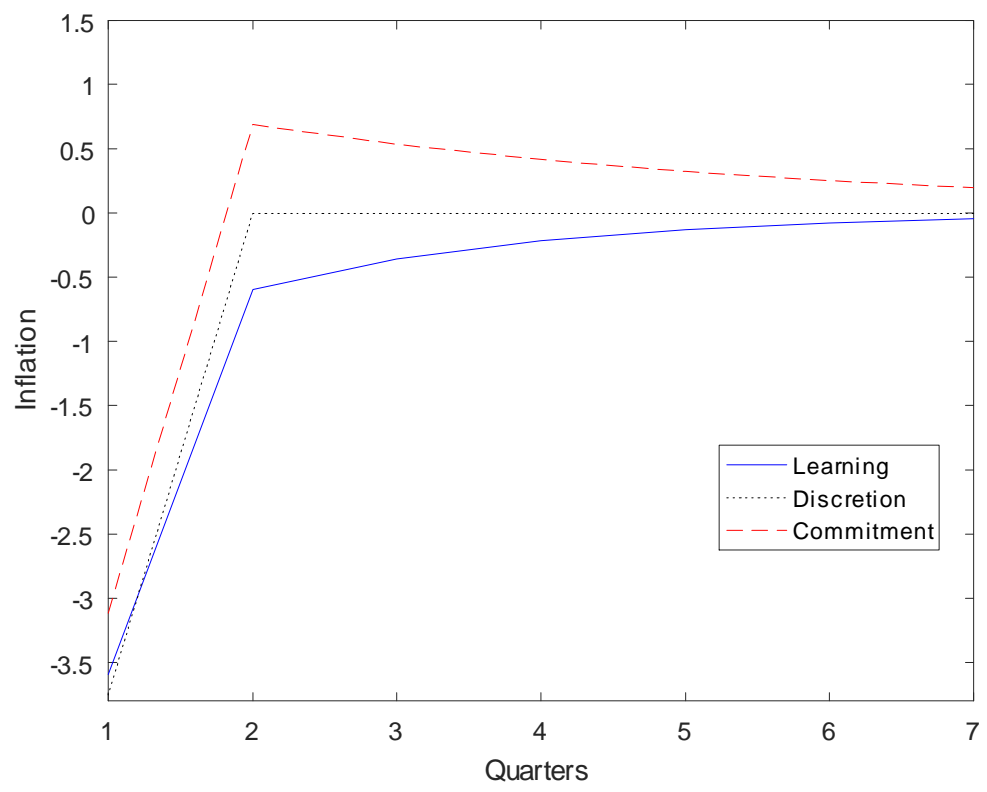

Figure 5: Impulse response to a negative cost-push shock, reducing inflation. The gain is set to $g=0.4$. The weight on the output gap is eight times the weight corresponding to the microfounded welfare function.

same inflation response. Indeed, taking the limit of the first-order conditions in the appendix as $g \rightarrow 0$ delivers precisely the rational expectations policy problem under discretion. ${ }^{16}$ If expectations are relatively well anchored - in the sense that long-run beliefs display low sensitivity to short-term forecast errors - the state-contingent evolution of inflation is suboptimal when compared to optimal commitment. Under the latter policy, inflation overshoots the steady-state inflation rate: by managing expectations a fully credible central bank can improve the short-run trade-off between the output gap and inflation. Perhaps surprisingly, when inflation expectations are poorly anchored, displaying drift in response to short-run forecast errors, optimal policy under learning looks more like optimal commitment. Figure 4 shows impulse responses with $g=0.4 .^{17}$ Inflation overshoots the long-run inflation rate under the optimal policy with learning, as the central bank aims to stabilize long-term inflation

\footnotetext{
${ }^{16}$ This result also applies to the current setting where the central bank has direct control of the output gap.

${ }^{17}$ This choice of gain is primarily for illustrative purposes. The model is too simple to make serious quantitative predictions. For example, if model features were included to generate empirically realistic strategic complementarities in price setting, the aggregate supply curve would be flatter and render the degree of overshooting larger for any given gain. Note also Carvalho, Eusepi, Moench, and Preston (2015) provide evidence, for various industrialized countries, of gains in the range of $0.1-0.25$ in periods in which expectations are poorly anchored.
} 
expectations. A simple numerical grid search reveals the basic properties of figure 4 appear to hold for all non-zero gains. ${ }^{18}$ While the impact effect on inflation tends to be larger than observed under discretion, the optimal policy under learning provides greater stabilization of the price level, by permitting a period of above steady-state inflation. These effects are larger, the greater the sensitivity of beliefs to short-run surprises.

History-dependence, a powerful policy tool under full credibility, is therefore also a desirable property when the central bank has less precise control of expectations - specifically when inflation expectations are poorly anchored or at the risk of becoming so. The crucial difference to optimal commitment policy is that history dependence under learning dynamics operates through actions not promises. Positive inflation surprises lift long-term inflation expectations closer to their long-term mean, and in so doing, restores some of the decline in the price level associated with optimal discretion. Confronted with poorly anchored inflation expectations the policy maker tolerates inflation overshooting as long as long-term inflation expectations are converging back to steady state. History dependence is therefore tied to the state of expectations. A further difference with commitment is that the incentive to stabilize the price level depends critically on the perceived costs arising from variations in real economic activity. In fact, there is a trade-off between short-term real stability and the stability of long-term inflation expectations. Figure 5 shows the case where $g=0.4$ and $\lambda_{x}$ is 8 times as large as in our baseline calibration when equal to the welfare-theoretic weight. While optimal commitment still displays overshooting, under learning inflation increases monotonically to its steady-state.

This feature of optimal policy contrasts sharply with the predictions of the Molnar and Santoro model, which does not display over-shooting. The policy problem is fundamentally different. Compare the aggregate supply curves in each model, conditional on the assumed belief structure:

$$
\pi_{t}=\kappa x_{t}+\kappa \frac{\alpha \beta}{1-\alpha \beta} a_{t-1}^{x}+\frac{(1-\alpha) \beta}{1-\alpha \beta} a_{t-1}^{\pi}+\mu_{t}
$$

and

$$
\pi_{t}=\kappa x_{t}+\beta a_{t-1}^{\pi}+\mu_{t}
$$

In our model, the aggregate supply curve has a short-run trade-off between inflation and the output gap that shifts in response to movements in both inflation and output gap beliefs; while in the Molnar and Santoro model the short-run trade-off depends only on inflation beliefs.

\footnotetext{
${ }^{18}$ This result appears to depend critically on the stabilization weight on the output gap being given by the welfare-theoretic weight. See further discussion below.
} 
The optimal policy problem therefore has one additional constraint, and also one additional channel to influence inflation outcomes. Over-shooting stems from this model property. A central bank with greater concern for inflation stabilization than outupt gap stabilization (such as the objective given by the welfare theoretic loss function) will use the output gap, and output gap beliefs, to stabilize inflation and long-run inflation beliefs close to target. This achieves the most favourable short-run trade-off. However, this is not always true. In economies with a high degree of nominal rigidity, or with a policy maker having a preference for output gap stability, over-shooting is not observed - there is monotonic convergence of inflation to steady state after a favorable cost-push shock.In both these cases the variability in the output gap required to shift the short-run trade-off through movements in long-run output beliefs is costly: either because high nominal rigidities require output to move substantially, or because there is preference to have more limited movement.

Summing up, optimal policy under learning can generate predictions that are close to commitment, delivering both a near-zero steady-state inflation rate and some overshooting in response to adverse supply shocks. The results are consistent with Woodford (2010) and Adam and Woodford (2012), where optimal policy is evaluated in an environment in which the central bank faces uncertainty about agents' expectations formation process. These papers sought to address the criticism that the history dependence of optimal commitment equilibrium relies on the unrealistically precise control of inflation expectations. Their central result is that history dependence remains a desirable feature of policy, despite the central bank not having full control of expectations. Our results extend these insights to environments where central bank announcements have absolutely no influence on beliefs.

\subsection{Patient central bank}

The previous sections demonstrate the presence of an intertemporal trade-off leads to lower long-term inflation when agents are more patient. This begs the question of whether for given household preferences a central bank that is more patient than society will also deliver lower inflation in equilibrium. Is there a "patient central bank" analogue to Rogoff's (1985) conservative central bank?

Suppose the central bank has discount factor $\tilde{\beta}$, which can be different from the household discount factor $\beta$. The policy problem becomes to minimize

$$
\mathbb{E}_{0} \sum_{t=0}^{\infty} \tilde{\beta}^{t}\left[\pi_{t}^{2}+\lambda_{x}\left(x_{t}-x^{*}\right)^{2}\right]
$$


subject to the five constraints (8)-(12) by choice of sequences $\left\{x_{t}, \pi_{t}, i_{t}, a_{t}^{\pi}, a_{t}^{x}, a_{t}^{i}\right\}$, taking as given initial beliefs $a_{-1}^{\pi}, a_{-1}^{x}$ and $a_{-1}^{i}$. Analogous calculations to the benchmark problem permits deriving the optimal long-run inflation rate to be

$$
\pi=\frac{\lambda_{x} \kappa x^{*}}{\kappa^{2} \Xi(\tilde{\beta} ; g, \beta)+\lambda_{x}(1-\beta)}
$$

where the function $\Xi(\tilde{\beta} ; g, \beta)$ is bounded below by unity and has the properties

$$
\lim _{g \rightarrow 0} \Xi(\tilde{\beta} ; g, \beta)=1
$$

and

$$
\frac{\partial \Xi(\tilde{\beta} ; g, \beta)}{\partial \tilde{\beta}}>0
$$

for positive gains. It follows that for given household preferences and beliefs, a patient central banker will give a lower long-term equilibrium inflation rate than observed under discretion.

In the limit of a very patient central banker, $\tilde{\beta} \rightarrow 1$, who values each period's loss equally

$$
\pi=\frac{\kappa \lambda_{x} x^{*}}{\kappa^{2} \frac{((1-\alpha \beta)+\kappa \alpha \beta)}{(1-\beta)}+\lambda_{x}(1-\beta)} .
$$

While the optimal inflation rate is always lower than discretion, a patient central bank does not deliver price stability. Interestingly optimal inflation is independent of the gain, which makes sense - a patient central banker who values losses equally finds no advantage in exploiting short-term expectations, no matter how quickly or slowly they adjust. Finally, note that welfare under a patient central bank will be lower than under the benchmark policy, since that policy is the optimal policy for the welfare-theoretic loss function.

\section{Discussion}

This final section provides brief commentary on various aspects of the optimal policy problem.

\subsection{On the Literature}

A number of papers have explored optimal policy in the New Keynesian model under learning dynamics. These include Gaspar, Smets and Vestin (2007, 2010), Molnar and Santoro (2013), Eusepi, Giannoni and Preston (2015) and Mele, Molnar, and Santoro (2015). The central difference to these analyses is the assumed loss function. Consistent with the underlying microfoundations, the policy problem assumes a distorted steady state, which implies 
the central bank seeks to deliver a positive steady-state output gap in equilibrium. While the merits of this assumption are discussed further below, it permits establishing a general property of policy under learning dynamics.

Earlier analyses, such as Sargent (1999) and Molnar and Santoro (2013), demonstrate the household's discount factor is critical to optimal policy outcomes, and specifically, their relation to optimal policy predictions under rational expectations. Sargent (1999), in a model of central bank learning with a rational private sector, shows that if the discount factor is unity then policy delivers the optimal commitment equilibrium. Values less than unity deliver optimal discretion. Molnar and Santoro (2013), which provides the analytical foundations of this analysis, instead study a model of private sector learning. They show that for discount factors less than unity, as the gain goes to zero the optimal discretion equilibrium obtains under learning. However, because they focus on the optimal response to shocks, rather than on the question of long-run inflation outcomes, their linear analysis is unable to consider the role of household patience in delivering optimal commitment - the belief structure analyzed fails to nest the form of expectations under optimal commitment, since such policies are history dependent.

This led to subsequent work by Mele, Molnar, and Santoro (2015) which studies the optimal response to disturbances when agents' beliefs nest those that obtain in both the discretion and commitment equilibria under rational expectations. They show that as beliefs converge when the gain goes to zero, optimal policy under learning converges to optimal discretion. While they don't analyze the limiting case of patience near unity, it is likely optimal commitment will obtain so long as the gain coefficient is bounded away from zero. The analysis presented here is identical in spirit. And while simplifying assumptions of our analytical work restrict attention to questions about the optimal long-run inflation rate, rather than on dynamic responses to shocks, it has the advantage of nesting both optimal commitment and discretion equilibria under rational expectations, while at the same time being a standard linear-quadratic control problem, rather than non-linear. As such it permits clean analytical conditions under which optimal discretion and optimal commitment outcomes will obtain, along with clear intuition for the determinants of long-run inflation. Stated differently, the contribution is to map Sargent's insights into the canonical New Keynesian model with household and firm learning dynamics. Doing so provides a useful frame of reference to interpret results from earlier literature on optimal policy under learning. 


\subsection{On Beliefs}

Despite the simplicity of the specification of beliefs, they are coherent with observed features of aggregate data. There is pervasive evidence that macroeconomic time series exhibit low-frequency movements, well captured by time-varying parameter models. This is true of inflation (see Stock and Watson, 2007; Cogley and Sbordone, 2008; Cogley, Primiceri and Sargent, 2010); output or the output gap (see Stock and Watson, 1989; Cogley and Sargent, 2005; Laubach and Williams, 2003); and nominal interest rates (see Kozicki and Tinsley, 2001; Gurkaynak, Sack and Swanson, 2005). Such models also capture quite well the evolution of short- and long-term surveys forecasts of these same time series. For example Branch and Evans (2006), Edge, Laubach, and Williams (2007), Kozicki and Tinsley (2012) and Crump, Eusepi and Moench (2016). And a related literature shows that small forecasting models, of the kind studied here, improve the fit of more complex models, such as the DSGE model of Smets and Wouters (2007) — see Ormeno and Molnar (2013), Orphanides and Williams (2005) and Slobodyan and Wouters (2012a).

Yet despite this evidence, most models used for policy evaluation either fail to account for such variation, or provide accounts that are dubitable. Most notably, models deployed for the evaluation of monetary policy, such as the Smets and Wouters (2007) model, attribute lowfrequency patterns in data to an exogenously determined drift in the central bank's long-run inflation objectives. While it would be difficult to dispute variation in policy maker preferences for inflation might explain some variation in observed inflation outcomes, its seems equally plausible that other mechanisms are at play. In particular, expectations themselves are likely to be a source of low-frequency variation in data. For example, Carvalho, Eusepi, Moench, and Preston (2015) adduce evidence that drifting long-run inflation expectations are important to explaining the great inflation of the 1970s and subsequent reduction in inflation over recent decades. ${ }^{19}$ Uncertainty about long-run properties of the economy, such as potential output and wages, or the central bank's inflation target, represent fundamental constraints on spending, hiring and pricing plans. If agents form inferences about these macroeconomic objectives using statistical methods that permit detection of low-frequency variation, then any decision based on such forecasts will inherit this drift. This paper, along with the earlier discussed literature, contributes to understanding optimal policy under such beliefs.

\footnotetext{
${ }^{19}$ See also Eusepi and Preston (2018).
} 


\subsection{On the Lucas Critique}

A possible objection to optimal policy analysis under learning dynamics is the Lucas critique. While such exercises are by assumption subject to this critique, there are limits to its relevance. First, any beliefs premised on a statistical filtering problem are subject to the same concerns. Second, despite this, it is not true that beliefs fail to adjust to a new policy regime. While the analysis assumes a fixed gain, so that there is a fixed mapping between short-term forecast errors and long-run beliefs, long-run beliefs are necessarily endogenous to policy through its effects on short-run forecast errors. This limits the extent to which a sophisticated central bank can manipulate beliefs. Indeed, in the long run, beliefs are consistent with equilibrium outcomes. Third, we assume a constant gain. In general the optimal gain will depend on the policy regime in place, and any serious quantitative exercise on optimal policy should account for this. We leave such analysis for future research. In the meantime, by studying the equilibrium implications under optimal policy implications of different values of this gain, we implicitly assume that the central bank, while informed, is not so sophisticated as to understand how the gain will evolve over time. In such a setup, even if a central bank could eventually drive the gain to zero, the inflation bias of optimal discretion would obtain. Alternatively, if policy ends up causing the gain to rise, then optimal policy would be resemble that of a commitment policy under rational expectations.

\subsection{On the Welfare Criterion}

The sub-optimality of discretion policy identified by Kydland and Prescott (1977) engendered a substantial literature on delegation. To the extent policy makers cannot commit, delegating alternative loss functions, that differ to the true welfare-theoretic loss function, could deliver welfare improvements. This led to Rogoff's (1985) conservative central banker, and other proposals - see Vestin (2000) for a discussion in the context of the New Keynesian policy analysis presented here. Most directly relevant, it led to the proposal that a central bank should be charged with minimizing the loss function (5) with $x^{*}=0$. Under such a loss function, the central bank, even though unable to commit, would deliver price stability in the long run.

Putting aside the merits of delegating loss functions — such approaches are likely to be problematic for central bank transparency and communications policy — it is important to recall there is no distinction between discretion and commitment under learning. Beliefs are state variables. It follows that if the central bank does inherit an environment in which there 
is a distorted steady state (because of monopolistic competition and distortionary taxes for example), then the optimal policy necessarily delivers a positive inflation rate. Delegating a welfare function in which $x^{*}=0$ will deliver inferior welfare outcomes if in fact there are economic reasons for a central bank to achieve an a positive output gap on average.

\section{Conclusion}

This paper demonstrates that price stability is in general not optimal when agents have beliefs that exhibit low-frequency drift. The optimal long-run inflation rate depends on all model parameters, though it is bounded by the optimal long-run inflation rates observed under discretion and commitment when agents have rational expectations. Interestingly, these rational expectations outcomes are delivered as special cases of the optimal policy model under learning. When the size of low-frequency drift is negligible, then optimal inflation coincides with the predictions under discretion. In contrast, for given low-frequency drift, if households are highly patient, price stability is optimal in the long run.

These insights extend to the optimal response to disturbances. When low-frequency drift in negligible, optimal discretion obtains, with associated stabilization bias and drift in the price level. When low-frequency drift in beliefs is more substantial, optimal policy acquires a crucial property of optimal commitment policy: in response to a negative supply shock, inflation is allowed to over-shoot its long-run mean, in order to stabilize the price level. 


\section{References}

Adam, K., J. Beutel, and A. Marcet (2017): "Stock Price Booms and Expected Capital Gains," forthcoming American Economic Review.

Adam, K., And M. Woodford (2012): "Robustly optimal monetary policy in a microfounded New Keynesian model," Journal of Monetary Economics, 59(5), 468-487.

Ascari, G., L. Phaneuf, and E. Sims (2015): "On the Welfare and Cyclical Implications of Moderate Trend Inflation," Nber working papers, National Bureau of Economic Research, Inc.

BAll, L. (2013): "The Case for Four Percent Inflation," Central Bank Review, 13(2), 17-31.

Blanchard, O., G. Dell'Ariccia, and P. Mauro (2010): "Rethinking Macroeconomic Policy," Journal of Money, Credit and Banking, 42(s1), 199-215.

Branch, W. A., And G. W. Evans (2006): "A Simple Recursive Forecasting Model," Economics Letters, (91), 158-166.

Bullard, J., And K. Mitra (2002): "Learning About Monetary Policy Rules," Journal of Monetary Economics, 49(6), 1105-1129.

Carvalho, C., S. Eusepi, E. Moench, and B. Preston (2015): "Anchored Inflation Expectations," unpublished manuscript, University of Melbourne.

Cogley, T., G. E. Primiceri, and T. J. Sargent (2010): "Inflation-Gap Persistence in the US," American Economic Journal: Macroeconomics, 2(1), 43-69.

Cogley, T., and T. J. Sargent (2005): "The Conquest of U.S. Inflation: Learning and Robustness to Model Uncertainty," Review of Economic Dynamics, 8(2), 528-563.

Cogley, T., And A. M. Sbordone (2008): "Trend Inflation, Indexation, and Inflation Persistence in the New Keynesian Phillips Curve," American Economic Review, 98(5), $2101-26$.

Coibion, O., Y. Gorodnichenko, and J. Wieland (2012): "The Optimal Inflation Rate in New Keynesian Models: Should Central Banks Raise Their Inflation Targets in Light of the Zero Lower Bound?," Review of Economic Studies, 79(4), 1371-1406. 
Crump, R., S. Eusepi, and E. Moench (2015): "The Term Structure of Expectations and Bond Yields," unpublished, Federal Reserve Bank of New York.

Edge, R., T. Laubach, and J. Williams (2007): "Learning and Shifts in Long-Run Productivity Growth," Journal of Monetary Economics, pp. 2421-2438.

Eusepi, S., M. Giannoni, and B. Preston (2015): "The Limits of Monetary Policy with Long-term Drift in Expectations," unpublished, The University of Melbourne.

Eusepi, S., And B. Preston (2011): "Expectations, Learning and Business Cycle Fluctuations," American Economic Review, 101(6), 2844-2872.

(2016): "The Science of Monetary Policy: An Imperfect Knowledge Perspective," forthcoming Journal of Economic Literature, The University of Melbourne.

(2018): "Fiscal Foundations of Inflation: Imperfect Knowledge," unpublished, The University of Melbourne.

Evans, G. W., and S. Honkapohja (2003): "Expectations and the Stability Problem for Optimal Monetary Policies," Review of Economic Studies, 70(4), 807-824.

Gaspar, V., F. Smets, and D. Vestin (2006): “Adaptive Learning, Persistence and Optimal Monetary Policy," Journal of the European Economics Association, 4, 376-385.

(2010): "Inflation Expectations, Adaptive Learning and Optimal Monetary Policy," in Handbook of Monetary Economics, ed. by B. M. Friedman, and M. Woodford, vol. 3 of Handbook of Monetary Economics, chap. 19, pp. 1055-1095. Elsevier.

Giannoni, M. P., And M. Woodford (2017): "Optimal Target Criteria for Stabilization Policy," Journal of Economic Theory, 168, 55-106.

Kozicki, S., And P. A. Tinsley (2001): "Shifting endpoints in the term structure of interest rates," Journal of Monetary Economics, 47(3), 613-652.

- (2012): "Effective Use of Survey Information in Estimating the Evolution of Expected Inflation," Journal of Money, Credit and Banking, 44(1), 145-169.

Kydland, F. E., and E. C. Prescott (1977): "Rules Rather than Discretion: The Inconsistency Problem of Optimal Plans," The Journal of Political Economy, 85(3), 473-492. 
Laubach, T., And J. C. Williams (2003): "Measuring the Natural Rate of Interest," The Review of Economics and Statistics, 85(4), 1063-1070.

Malmendier, U., And S. Nagel (2016): "Learning from Inflation Experiences," The Quarterly Journal of Economics, 131(1), 53-87.

Mele, A., K. Molnar, and S. Santoro (2015): "On the perils of stabilizing prices when agents are learning," School of economics discussion papers, School of Economics, University of Surrey.

Milani, F. (2011): "Expectation Shocks and Learning as Drivers of the Business Cycle," Economic Journal, 121(552), 379-401.

Molnar, K., And S. Santoro (2013): "Optimal Monetary Policy When Agents Are Learning," European Economic Review, 66, 39-62.

Ormeno, A., And K. Molnar (2013): "Using Survey Data of Inflation Expectations in the Estimation of Learning and Rational Expectations Models," manuscript, Norwegan School of Economics.

Orphanides, A., And J. C. Williams (2005): "The decline of activist stabilization policy: Natural rate misperceptions, learning, and expectations," Journal of Economic Dynamics and Control, 29(11), 1927-1950.

Preston, B. (2005): "Learning About Monetary Policy Rules when Long-Horizon Expectations Matter," International Journal of Central Banking, 1(2), 81-126.

Rogoff, K. (1985): "The Optimal Degree of Commitment to an Intermediate Monetary Target," The Quarterly Journal of Economics, 100(4), 1169-1189.

Sargent, T., N. Williams, and T. Zha (2006): "Shocks and Government Beliefs: The Rise and Fall of American Inflation," American Economic Review, 96(4), 1193-1224.

Sargent, T. J. (1999): The Conquest of American Inflation. Princeton University Press.

Slobodyan, S., and R. Wouters (2012a): "Learning in a Medium-Scale DSGE Model with Expectations Based on Small Forecasting Models," American Economic Journal: Macroeconomics, 4(2), 65-101. 
- (2012b): "Learning in an estimated medium-scale DSGE model," Journal of Economic Dynamics and Control, 36(1), 26-46.

Smets, F., And R. Wouters (2007): "Shocks and Frictions in US Business Cycles: a Bayesian DSGE Approach," American Economic Review, 97(3), 586-606.

Stock, J. H., and M. W. Watson (2007): "Why Has U.S. Inflation Become Harder to Forecast?," Journal of Money, Credit and Banking, 39(s1), 3-33.

Vestin, D. (2000): "Price-level targeting versus inflation targeting in a forward-looking model," IIES, Stockholn University mimeo.

Woodford, M. (2003): Interest and Prices: Foundations of a Theory of Monetary Policy. Princeton University Press.

(2010): "Robustly Optimal Monetary Policy with Near-Rational Expectations," American Economic Review, 100(1), 274-303. 


\section{A Appendix}

The optimal policy problem is to minimize the loss (5) subject to the five constraints (8)-(12). The Lagrangian is:

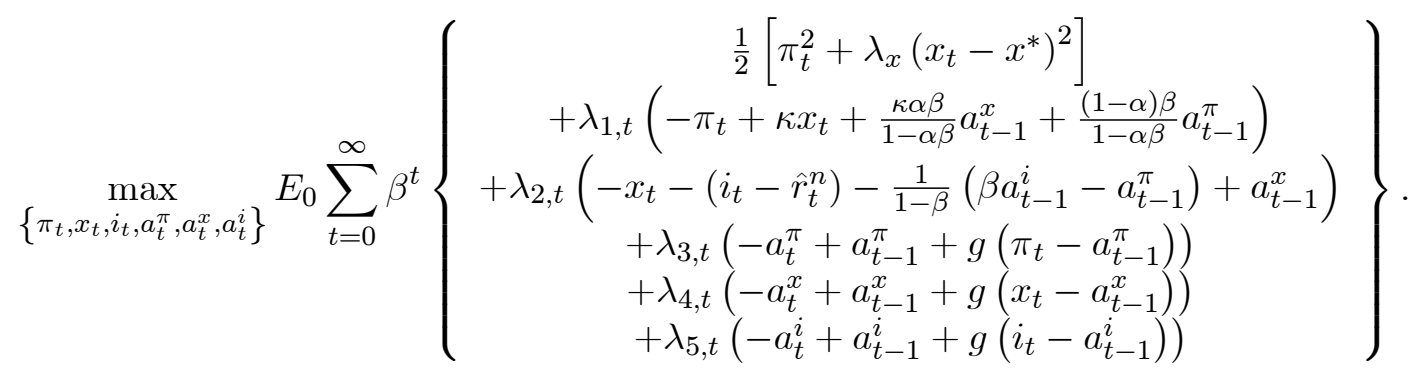

The first-order conditions are:

$$
\begin{aligned}
\pi_{t}-\lambda_{1, t}+g \lambda_{3, t} & =0 \\
\lambda_{x}\left(x_{t}-x^{*}\right)+\lambda_{1, t} \kappa-\lambda_{2, t}+\lambda_{4, t} g & =0 \\
\frac{\kappa \alpha \beta}{1-\alpha \beta} \beta E_{t} \lambda_{1, t+1}-\lambda_{4, t}+\beta(1-g) E_{t} \lambda_{4, t+1}+\beta E_{t} \lambda_{2, t+1} & =0 \\
\frac{(1-\alpha) \beta}{1-\alpha \beta} \beta E_{t} \lambda_{1, t+1}+\frac{\beta}{1-\beta} E_{t} \lambda_{2, t+1}-\lambda_{3, t}+\beta(1-g) E_{t} \lambda_{3, t+1} & =0 \\
g \lambda_{5, t}-\lambda_{2, t} & =0 \\
-\lambda_{5, t}+\beta(1-g) E_{t} \lambda_{5, t+1}-\frac{\beta^{2}}{1-\beta} E_{t} \lambda_{2, t+1} & =0 .
\end{aligned}
$$

\section{A.1 Proof of Proposition 2: Steady State}

The proof proceeds in two steps. First, compute the steady state rate of inflation to verify the value given in proposition. Second, prove that the optimal policy problem has a unique bounded solution in which dynamics converge to this steady state.

In steady state (19) and (20) imply $\lambda_{2}=\lambda_{5}=0$.Using relations (16) and (17) imply

$$
\lambda_{x}\left(x-x^{*}\right)=-\lambda_{1} \kappa\left(1+\frac{\alpha \beta^{2}}{1-\alpha \beta} \frac{g}{1-\beta(1-g)}\right)
$$

and using the Phillips curve in steady state provides

$$
\lambda_{x}\left(\frac{(1-\beta) \pi}{\kappa}-x^{*}\right)=-\lambda_{1} \kappa\left(1+\frac{\alpha \beta^{2}}{1-\alpha \beta} \frac{g}{1-\beta(1-g)}\right) .
$$

Now (15) and (18) imply

$$
\begin{aligned}
\pi & =\lambda_{1}\left(1-\frac{g}{1-\beta(1-g)} \frac{(1-\alpha) \beta^{2}}{1-\alpha \beta}\right) \\
& =\frac{\lambda_{x}\left(x^{*}-\frac{(1-\beta) \pi}{\kappa}\right)}{\kappa\left(1+\frac{\alpha \beta^{2}}{1-\alpha \beta} \frac{g}{1-\beta(1-g)}\right)}\left(1-\frac{g}{1-\beta(1-g)} \frac{(1-\alpha) \beta^{2}}{1-\alpha \beta}\right)
\end{aligned}
$$


and hence

$$
\pi\left[\begin{array}{c}
\kappa\left(1+\frac{\alpha \beta^{2}}{1-\alpha \beta} \frac{g}{1-\beta(1-g)}\right) \\
+\lambda_{x} \frac{(1-\beta)}{\kappa}\left(1-\frac{g}{1-\beta(1-g)} \frac{(1-\alpha) \beta^{2}}{1-\alpha \beta}\right)
\end{array}\right]=\lambda_{x} x^{*}\left(1-\frac{g}{1-\beta(1-g)} \frac{(1-\alpha) \beta^{2}}{1-\alpha \beta}\right) .
$$

The steady-state inflation rate is given by

$$
\begin{aligned}
\pi & =\frac{\lambda_{x} x^{*}\left(1-\frac{g}{1-\beta(1-g)} \frac{(1-\alpha) \beta^{2}}{1-\alpha \beta}\right)}{\kappa\left(1+\frac{\alpha \beta^{2}}{1-\alpha \beta} \frac{g}{1-\beta(1-g)}\right)+\lambda_{x} \frac{(1-\beta)}{\kappa}\left(1-\frac{g}{1-\beta(1-g)} \frac{(1-\alpha) \beta^{2}}{1-\alpha \beta}\right)} \\
& =\frac{\kappa \lambda_{x} x^{*}}{\kappa^{2} \frac{g \beta+(1-\beta)(1-\alpha \beta)}{g \beta(1-\beta)+(1-\beta)(1-\alpha \beta)}+\lambda_{x}(1-\beta)}
\end{aligned}
$$

as required.

Evaluating the model's equations (8)-(12) in steady state yields

$$
\begin{aligned}
\pi & =\kappa x+\frac{\kappa \alpha \beta}{1-\alpha \beta} a^{x}+\frac{(1-\alpha) \beta}{1-\alpha \beta} a^{\pi} \\
x & =-\left(i-\hat{r}^{n}\right)-\frac{1}{1-\beta}\left(\beta a^{i}-a^{\pi}\right)+a^{x} \\
a^{\pi} & =\pi \\
a^{x} & =x \\
a^{i} & =i
\end{aligned}
$$

or

$$
\begin{aligned}
& \pi=\kappa x+\frac{\kappa \alpha \beta}{1-\alpha \beta} x+\frac{(1-\alpha) \beta}{1-\alpha \beta} \pi \\
& x=-\left(i-\hat{r}^{n}\right)-\frac{1}{1-\beta}(\beta i-\pi)+x
\end{aligned}
$$

This implies in turn the steady-state output gap

and the steady state interest rate

$$
x=\frac{1-\beta}{\kappa} \pi
$$

$$
i=(1-\beta) \hat{r}^{n}+\pi
$$

where $\hat{r}^{n}=0$ in steady state.

\section{A.2 Proof of Proposition 2: Equilibrium Dynamics}

We now show that under optimal policy, the equilibrium dynamics are unique and bounded. Consider the vector of $m=6$ endogenous variables $y_{t}=\left[\tilde{\pi}_{t}, \tilde{x}_{t}, \tilde{\imath}_{t}, \tilde{a}_{t}^{\pi}, \tilde{a}_{t}^{x}, \tilde{a}_{t}^{i}\right]^{\prime}$ where the tilde denotes the fact that the variables are expressed in deviations from the steady state characterized above. The $n=5$ structural equations (8)-(12) can be written compactly in the form

$$
\left[\begin{array}{cccccc}
1 & -\kappa & 0 & 0 & 0 & 0 \\
0 & 1 & 1 & 0 & 0 & 0 \\
-g & 0 & 0 & 1 & 0 & 0 \\
0 & -g & 0 & 0 & 1 & 0 \\
0 & 0 & -g & 0 & 0 & 1
\end{array}\right]\left[\begin{array}{c}
\tilde{\pi}_{t} \\
\tilde{x}_{t} \\
\tilde{u}_{t} \\
\tilde{a}_{t}^{\pi} \\
\tilde{a}_{t}^{x} \\
\tilde{a}_{t}^{i}
\end{array}\right]=\left[\begin{array}{cccccc}
0 & 0 & 0 & \frac{(1-\alpha) \beta}{1-\alpha \beta} & \frac{\kappa \alpha \beta}{1-\alpha \beta} & 0 \\
0 & 0 & 0 & \frac{1}{1-\beta} & 1 & -\frac{\beta}{1-\beta} \\
0 & 0 & 0 & 1-g & 0 & 0 \\
0 & 0 & 0 & 0 & 1-g & 0 \\
0 & 0 & 0 & 0 & 0 & 1-g
\end{array}\right]\left[\begin{array}{c}
\tilde{\pi}_{t-1} \\
\tilde{x}_{t-1} \\
\tilde{v}_{t-1} \\
\tilde{a}_{t-1}^{\pi} \\
\tilde{a}_{t-1}^{x} \\
\tilde{a}_{t-1}^{i}
\end{array}\right]+\left[\begin{array}{c}
0 \\
1 \\
0 \\
0 \\
0
\end{array}\right] \hat{r}_{t}^{n}
$$


or

$$
\bar{I} y_{t}=\bar{A} y_{t-1}+\bar{C} \hat{r}_{t}^{n}
$$

where

$$
\bar{I}=\beta\left[\begin{array}{cccccc}
1 & -\kappa & 0 & 0 & 0 & 0 \\
0 & 1 & 1 & 0 & 0 & 0 \\
-g & 0 & 0 & 1 & 0 & 0 \\
0 & -g & 0 & 0 & 1 & 0 \\
0 & 0 & -g & 0 & 0 & 1
\end{array}\right], \quad \bar{A}=\beta\left[\begin{array}{cccccc}
0 & 0 & 0 & \frac{(1-\alpha) \beta}{1-\alpha \beta} & \frac{\kappa \alpha \beta}{1-\alpha \beta} & 0 \\
0 & 0 & 0 & \frac{1}{1-\beta} & 1 & -\frac{\beta}{1-\beta} \\
0 & 0 & 0 & 1-g & 0 & 0 \\
0 & 0 & 0 & 0 & 1-g & 0 \\
0 & 0 & 0 & 0 & 0 & 1-g
\end{array}\right], \quad \bar{C}=\beta\left[\begin{array}{l}
0 \\
1 \\
0 \\
0 \\
0
\end{array}\right]
$$

The $m=6$ first-order conditions (15)-(20) can be written as

$$
\bar{A}^{\prime} E_{t} \lambda_{t+1}=\beta^{-1} \bar{I}^{\prime} \lambda_{t}-S y_{t},
$$

where $\lambda_{t}=\left[\lambda_{1, t} \ldots, \lambda_{5, t}\right]^{\prime}$ is a vector of $n$ non-predetermined Lagrange multipliers, and $S$ is a diagonal matrix with $\left[1, \lambda_{x}, 0,0,0,0\right]$ on the diagonal. Combining the equilibrium conditions and FOCs, we obtain a system of 11 dynamic equations in 11 variables

$$
M E_{t}\left[\begin{array}{c}
\lambda_{t+1} \\
y_{t}
\end{array}\right]=N\left[\begin{array}{c}
\lambda_{t} \\
y_{t-1}
\end{array}\right]+\left[\begin{array}{c}
0 \\
\bar{C}
\end{array}\right] \hat{r}_{t}^{n}
$$

where

$$
M=\left[\begin{array}{cc}
\bar{A}^{\prime} & S \\
0 & \bar{I}
\end{array}\right], \quad \text { and } \quad N=\left[\begin{array}{cc}
\beta^{-1} \bar{I}^{\prime} & 0 \\
0 & \bar{A}
\end{array}\right] .
$$

Given that the dynamic system (22) has six predetermined variables, $y_{t-1}$, and five non-predetermined variables, $\lambda_{t}$, this system admits a unique bounded solution if five of the generalized eigenvalues of $N$ and $M$ - i.e., the roots of $\operatorname{det}(\mu M-N)=0$ - lie outside the unit circle while six lie inside. We can show that the characteristic polynomial satisfies

$$
\begin{aligned}
\operatorname{det}(\phi M-\rho N)= & \frac{-\beta^{5}}{(1-\beta)^{2}} \phi^{3} \rho^{2}(\phi-\rho(1-g))(\phi \beta(1-g)-\rho)((1-\beta) \phi+\rho(g+\beta-1)) \\
& \times((g+\beta-1) \beta \phi+\rho(1-\beta))\left(\beta a_{1} \phi^{2}+a_{2} \rho \phi+\rho^{2} a_{1}\right)
\end{aligned}
$$

where

$$
\begin{aligned}
& a_{1}=\left(\left(1-\beta \frac{1-\alpha}{1-\alpha \beta}\right) g-1\right) \lambda_{x}+\kappa^{2}\left(g \frac{1}{1-\alpha \beta}-1\right) \\
& a_{2}=\left(1+\beta\left(1-g \frac{1-\beta}{1-\alpha \beta}\right)^{2}\right) \lambda_{x}+\kappa^{2}\left(1+\beta\left(1-g \frac{1}{1-\alpha \beta}\right)^{2}\right)>0 .
\end{aligned}
$$

This can equivalently be written as the product of 11 factors of the form $\left(\alpha_{i} \phi-\beta_{i} \rho\right)$ for some complex numbers $\alpha_{i}$ and $\beta_{i}$. The generalized eigenvalues of the matrix pencil $\mu M-N$ are the quantities $\mu=\phi / \rho=\beta_{i} / \alpha_{i}$. The 3 factors $\phi^{3}$ for which $\beta_{i}=0$ correspond to the 3 zero eigenvalues of $\mu M-N$. The two factors $\rho^{2}$ for which $\alpha_{i}=0$ corresponds to the "infinite" eigenvalues of $\mu M-N$. Furthermore, one eigenvalue solves $\left(\mu_{6}-(1-g)\right)=0$, or $\mu_{6}=1-g \in(0,1)$; and one solves $\left(\mu_{7} \beta(1-g)-1\right)=0$, or $\mu_{7}=\beta^{-1}(1-g)^{-1}>1$. 
The next two eigenvalues solve $(1-\beta) \mu_{8}+(g+\beta-1)=0$ or $\mu_{8}=\frac{1-\beta-g}{1-\beta}$, and $(g+\beta-1) \beta \mu_{9}$ $+(1-\beta)=0$, or $\mu_{9}=\frac{1-\beta}{(1-\beta-g) \beta}$. As discussed further below, the dynamic system $(22)$ admits a unique bounded solution provided that one of the eigenvalues $\mu_{8}, \mu_{9}$ is inside the unit circle while the other is outside the unit circle. Note that $\mu_{9}=\frac{1}{\mu_{8} \beta}$. If the first satisfies $\left|\mu_{8}\right|<1$, then the second satisfies $\left|\mu_{9}\right|=\left|\frac{1}{\mu_{8} \beta}\right|>1$. If $\left|\mu_{8}\right|>\beta^{-1}$, then $\left|\mu_{9}\right|=\left|\frac{1}{\mu_{8} \beta}\right|<1$. However if $1<\left|\mu_{8}\right|<\beta^{-1}$, then $\left|\mu_{9}\right|=\left|\frac{1}{\mu_{8} \beta}\right|>1$, in which case both $\mu_{8}$ and $\mu_{9}$ are explosive roots. The eigenvalues $\mu_{8}$ and $\mu_{9}$ are on both sides of the unit circle provided that $\mu_{8}=\frac{1-\beta-g}{1-\beta}$ satisfies either $\left|\mu_{8}\right|<1$ or $\left|\mu_{8}\right|>\beta^{-1}$, or equivalently if $g$ satisfies either (i) $|1-\beta-g|<1-\beta$ or (ii) $|1-\beta-g|>\beta^{-1}(1-\beta)=\beta^{-1}-1$. Suppose first that $0<g \leq 1-\beta$. Condition (i) is then automatically satisfied. Alternatively, suppose that $g>1-\beta$, then condition (i) can be rewritten as $g<2(1-\beta)$, and condition (ii) can be rewritten as $g>\beta^{-1}-\beta$. So, $\mu_{8}$ and $\mu_{9}$ are on both sides of the unit circle provided that $g$ satisfies either $g<2(1-\beta)$ or $g>\beta^{-1}-\beta$.

The last two eigenvalues of $\mu M-N$ solve the characteristic equation

$$
q(\mu) \equiv \beta \mu^{2}+\frac{a_{2}}{a_{1}} \mu+1=0,
$$

where the polynomial $q(\mu)$ has the property $q(0)=1>0$. The polynomial $q(\mu)$ has one real root $\mu_{10}$ inside the unit circle and one root $\mu_{11}$ outside if either $q(1)<1$ or $q(-1)<1$. We have $q(1)<1$ if and only if $g<\frac{(1-\alpha \beta)\left(\lambda_{x}+\kappa^{2}\right)}{\lambda_{x}(1-\beta)+\kappa^{2}} ; q(-1)<0$ if $g>\frac{(1-\alpha \beta)\left(\lambda_{x}+\kappa^{2}\right)}{\lambda_{x}(1-\beta)+\kappa^{2}}$ and $g$ satisfies either $g<2(1-\alpha \beta)$ or $g>\left(\beta^{-1}+1\right)(1-\alpha \beta)$.

The matrix polynomial $\mu M-N$ has thus six generalized eigenvalues inside the unit circle $\left(0,0,0,1-g, \mu_{8}, \mu_{10}\right)$, and five eigenvalues outside the unit circle $\left(\mu_{9}, \mu_{11}, \beta^{-1}(1-g)^{-1}, \infty, \infty\right)$, provided that $g$ satisfies either $g<2(1-\beta)$ or $g>\beta^{-1}-\beta$, and, in case $g>\frac{(1-\alpha \beta)\left(\lambda_{x}+\kappa^{2}\right)}{\lambda_{x}(1-\beta)+\kappa^{2}}$, it satisfies either $g<2(1-\alpha \beta)$ or $g>\left(\beta^{-1}+1\right)(1-\alpha \beta)$. Given that the dynamic system (22) has six predetermined variables, $y_{t-1}$, and five non-predetermined variables, $\lambda_{t}$, this system admits a unique bounded solution, if $g$ meets the above conditions. As the first three columns of the matrix $\bar{A}$ are all zero, initial conditions for $\pi_{t-1}, x_{t-1}, i_{t-1}$ are irrelevant. It suffices to specify initial conditions for the three variables $a_{t-1}^{\pi}, a_{t-1}^{x}, a_{t-1}^{i}$. 


\section{B Additional Results Not For Publication}

The matrices $M$ and $N$ of the characteristic polynomial $\operatorname{det}(\phi M-\rho N)$ are:

$$
\begin{aligned}
& M=\left[\begin{array}{ccccccccccc}
0 & 0 & 0 & 0 & 0 & 1 & 0 & 0 & 0 & 0 & 0 \\
0 & 0 & 0 & 0 & 0 & 0 & \lambda_{x} & 0 & 0 & 0 & 0 \\
0 & 0 & 0 & 0 & 0 & 0 & 0 & 0 & 0 & 0 & 0 \\
\beta^{2} \frac{1-\alpha}{1-\alpha \beta} & \frac{\beta}{1-\beta} & \beta(1-g) & 0 & 0 & 0 & 0 & 0 & 0 & 0 & 0 \\
\frac{\alpha \kappa \beta^{2}}{1-\alpha \beta} & \beta & 0 & \beta(1-g) & 0 & 0 & 0 & 0 & 0 & 0 & 0 \\
0 & -\frac{\beta^{2}}{1-\beta} & 0 & 0 & \beta(1-g) & 0 & 0 & 0 & 0 & 0 & 0 \\
0 & 0 & 0 & 0 & 0 & \beta & -\beta \kappa & 0 & 0 & 0 & 0 \\
0 & 0 & 0 & 0 & 0 & 0 & \beta & \beta & 0 & 0 & 0 \\
0 & 0 & 0 & 0 & 0 & -\beta g & 0 & 0 & \beta & 0 & 0 \\
0 & 0 & 0 & 0 & 0 & 0 & -\beta g & 0 & 0 & \beta & 0 \\
0 & 0 & 0 & 0 & 0 & 0 & 0 & -\beta g & 0 & 0 & \beta
\end{array}\right] \\
& N=\left[\begin{array}{ccccccccccc}
1 & 0 & -g & 0 & 0 & 0 & 0 & 0 & 0 & 0 & 0 \\
-\kappa & 1 & 0 & -g & 0 & 0 & 0 & 0 & 0 & 0 & 0 \\
0 & 1 & 0 & 0 & -g & 0 & 0 & 0 & 0 & 0 & 0 \\
0 & 0 & 1 & 0 & 0 & 0 & 0 & 0 & 0 & 0 & 0 \\
0 & 0 & 0 & 1 & 0 & 0 & 0 & 0 & 0 & 0 & 0 \\
0 & 0 & 0 & 0 & 1 & 0 & 0 & 0 & 0 & 0 & 0 \\
0 & 0 & 0 & 0 & 0 & 0 & 0 & 0 & \frac{(1-\alpha) \beta^{2}}{1-\alpha \beta} & \frac{\kappa \alpha \beta^{2}}{1-\alpha \beta} & 0 \\
0 & 0 & 0 & 0 & 0 & 0 & 0 & 0 & \frac{\beta}{1-\beta} & \beta & -\frac{\beta^{2}}{1-\beta} \\
0 & 0 & 0 & 0 & 0 & 0 & 0 & 0 & \beta(1-g) & 0 & 0 \\
0 & 0 & 0 & 0 & 0 & 0 & 0 & 0 & 0 & \beta(1-g) & 0 \\
0 & 0 & 0 & 0 & 0 & 0 & 0 & 0 & 0 & 0 & \beta(1-g)
\end{array}\right] .
\end{aligned}
$$

The characteristic polynomial $\operatorname{det}(\phi M-\rho N)$

$$
=\mid \begin{array}{ccccccccccc}
-\rho & 0 & g \rho & 0 & 0 & \phi & 0 & 0 & 0 & 0 & 0 \\
\kappa \rho & -\rho & 0 & g \rho & 0 & 0 & \phi \lambda_{x} & 0 & 0 & 0 & 0 \\
0 & -\rho & 0 & 0 & g \rho & 0 & 0 & 0 & 0 & 0 & 0 \\
\beta^{2} \phi(1-\alpha) \eta & \frac{\beta \phi}{1-\beta} & \psi & 0 & 0 & 0 & 0 & 0 & 0 & 0 & 0 \\
\alpha \kappa \beta^{2} \phi \eta & \beta \phi & 0 & \psi & 0 & 0 & 0 & 0 & 0 & 0 & 0 \\
0 & -\frac{\beta^{2} \phi}{1-\beta} & 0 & 0 & \psi & 0 & 0 & 0 & 0 & 0 & 0 \\
0 & 0 & 0 & 0 & 0 & \beta \phi & -\kappa \beta \phi & 0 & -\beta^{2} \rho(1-\alpha) \eta & -\alpha \kappa \beta^{2} \rho \eta & 0 \\
0 & 0 & 0 & 0 & 0 & 0 & \beta \phi & \beta \phi & \beta \frac{\rho}{\beta-1} & -\beta \rho & \frac{\beta^{2} \rho}{1-\beta} \\
0 & 0 & 0 & 0 & 0 & -g \beta \phi & 0 & 0 & \delta & 0 & 0 \\
0 & 0 & 0 & 0 & 0 & 0 & -g \beta \phi & 0 & 0 & \delta & 0 \\
0 & 0 & 0 & 0 & 0 & 0 & 0 & -g \beta \phi & 0 & 0 & \delta
\end{array} \text {, }
$$

where $\eta=\frac{1}{1-\alpha \beta}, \psi=\beta \phi(1-g)-\rho, \delta=\beta(\phi-\rho(1-g))$. 
Expanding and rearranging terms, we obtain:

$$
\begin{aligned}
& \operatorname{det}(\phi M-\rho N) \\
= & \frac{\beta^{2} \phi^{3} \rho^{2} \delta \psi}{(1-\beta)^{2}}\left(g \rho \beta^{2}-\delta \beta+\delta\right)\left(g \phi \beta^{2}+\psi \beta-\psi\right) \\
& \times\left(\left(\psi+g \beta^{2} \phi \eta(1-\alpha)\right)\left(\delta-g \beta^{2} \eta \rho(1-\alpha)\right) \lambda_{x}+\kappa^{2}\left(\psi-g \alpha \beta^{2} \phi \eta\right)\left(g \alpha \eta \rho \beta^{2}+\delta\right)\right) \\
= & \frac{\beta^{4} \phi^{3} \rho^{2}}{(1-\beta)^{2}}(\phi-\rho(1-g))(\beta \phi(1-g)-\rho)((1-\beta) \phi+\rho(g+\beta-1))((g+\beta-1) \beta \phi+\rho(1-\beta)) p
\end{aligned}
$$

where

$$
\begin{aligned}
p= & \left(\beta \phi(1-g)+g \beta^{2} \phi \eta(1-\alpha)-\rho\right)\left(\beta(\phi-\rho(1-g))-g \beta^{2} \eta(1-\alpha) \rho\right) \lambda_{x} \\
& +\kappa^{2}\left(\beta \phi-\rho-g \beta \phi-g \alpha \beta^{2} \phi \eta\right)\left(g \alpha \eta \rho \beta^{2}+\beta(\phi-\rho(1-g))\right) \\
= & -\beta\left(\beta a_{1} \phi^{2}+a_{2} \rho \phi+\rho^{2} a_{1}\right)
\end{aligned}
$$

and

$$
\begin{aligned}
& a_{1}=-\left(1-\frac{1-\beta}{1-\alpha \beta} g\right) \lambda_{x}-\kappa^{2}\left(1-g \frac{1}{1-\alpha \beta}\right) \\
& a_{2}=\left(1+\beta\left(1-g \frac{1-\beta}{1-\alpha \beta}\right)^{2}\right) \lambda_{x}+\kappa^{2}\left(1+\beta\left(1-g \frac{1}{1-\alpha \beta}\right)^{2}\right)>0 .
\end{aligned}
$$

It is useful to rewrite the polynomial $p$ as $p=-\beta a_{1} \rho^{2} q\left(\frac{\phi}{\rho}\right)$, where the polynomial

$$
q(\mu) \equiv \beta \mu^{2}+\frac{a_{2}}{a_{1}} \mu+1
$$

has the following properties:

$$
q(0)>0
$$

and

$$
\begin{aligned}
q(1) & =\beta+\frac{a_{2}}{a_{1}}+1 \\
& =\frac{\frac{g}{(1-\alpha \beta)^{2}}\left((1-\beta)^{2}(g \beta-\alpha \beta+1) \lambda_{x}+\kappa^{2}\left(g \beta-\beta-\alpha \beta+\alpha \beta^{2}+1\right)\right)}{\left(\left(1-\beta \frac{1-\alpha}{1-\alpha \beta}\right) g-1\right) \lambda_{x}+\kappa^{2}\left(g \frac{1}{1-\alpha \beta}-1\right)} \\
& =\frac{\frac{g}{(1-\alpha \beta)}\left(\left(\lambda_{x}(1-\beta)^{2}+\kappa^{2}\right) \beta g+(1-\beta)(1-\alpha \beta)\left(\lambda_{x}(1-\beta)+\kappa^{2}\right)\right)}{\left(\lambda_{x}(1-\beta)+\kappa^{2}\right) g-(1-\alpha \beta)\left(\lambda_{x}+\kappa^{2}\right)}
\end{aligned}
$$

is negative if and only if $\left(\lambda_{x}(1-\beta)+\kappa^{2}\right) g<(1-\alpha \beta)\left(\lambda_{x}+\kappa^{2}\right)$. So we have $q(1)<0$ if and only if

$$
g<\frac{(1-\alpha \beta)\left(\lambda_{x}+\kappa^{2}\right)}{\lambda_{x}(1-\beta)+\kappa^{2}} .
$$


Moreover,

$$
\begin{aligned}
q(-1) & =\beta-\frac{a_{2}}{a_{1}}+1 \\
& =1+\beta+\frac{\left(1+\beta\left(1-g \frac{1-\beta}{1-\alpha \beta}\right)^{2}\right) \lambda_{x}+\kappa^{2}\left(1+\beta\left(1-g \frac{1}{1-\alpha \beta}\right)^{2}\right)}{\left(1-\frac{1-\beta}{1-\alpha \beta} g\right) \lambda_{x}+\kappa^{2}\left(1-g \frac{1}{1-\alpha \beta}\right)} \\
& =\frac{\text { num }}{-\frac{1}{1-\alpha \beta}\left(\left(\lambda_{x}(1-\beta)+\kappa^{2}\right) g-(1-\alpha \beta)\left(\lambda_{x}+\kappa^{2}\right)\right)}
\end{aligned}
$$

where the numerator

$$
\begin{aligned}
\text { num }= & {\left[\beta\left(1-g \frac{1-\beta}{1-\alpha \beta}\right)^{2}+(1+\beta)\left(1-\frac{1-\beta}{1-\alpha \beta} g\right)+1\right] \lambda_{x} } \\
& +\kappa^{2}\left[\beta\left(1-g \frac{1}{1-\alpha \beta}\right)^{2}+(1+\beta)\left(1-g \frac{1}{1-\alpha \beta}\right)+1\right] .
\end{aligned}
$$

The first term in square brackets is positive since $0<\frac{1-\beta}{1-\alpha \beta}<1$. The second term in square brackets equals $\frac{\beta}{(1-\alpha \beta)^{2}} g^{2}-\frac{3 \beta+1}{1-\alpha \beta} g+2(\beta+1)$, a quadratic polynomial in $g$ that admits two roots: $2(1-\alpha \beta)$ and $\left(\beta^{-1}+1\right)(1-\alpha \beta)$. It is positive if $g<2(1-\alpha \beta)$ or if $g>\left(\beta^{-1}+1\right)(1-\alpha \beta)$. The denominator is negative if and only if $\left(\lambda_{x}(1-\beta)+\kappa^{2}\right) g>(1-\alpha \beta)\left(\lambda_{x}+\kappa^{2}\right)$. So we have $q(-1)<0$ if

$$
g>\frac{(1-\alpha \beta)\left(\lambda_{x}+\kappa^{2}\right)}{\lambda_{x}(1-\beta)+\kappa^{2}},
$$

and $g$ satisfies either $g<2(1-\alpha \beta)$ or $g>\left(\beta^{-1}+1\right)(1-\alpha \beta)$. This is a sufficient but not necessary condition for $q(-1)$ to be negative.

A necessary condition for $q(-1)$ to be negative involves $g>\frac{(1-\alpha \beta)\left(\lambda_{x}+\kappa^{2}\right)}{\lambda_{x}(1-\beta)+\kappa^{2}}$, and the entire numerator to be positive. This numerator,

$$
\text { num }=\frac{\beta\left(\lambda_{x}(1-\beta)^{2}+\kappa^{2}\right)}{(1-\alpha \beta)^{2}} g^{2}-\left(\lambda_{x}(1-\beta)+\kappa^{2}\right) \frac{1+3 \beta}{1-\alpha \beta} g+(2 \beta+2)\left(\lambda_{x}+\kappa^{2}\right)
$$

is a quadratic polynomial in $g$ that admits the two roots:

$$
\begin{aligned}
g_{1}= & \frac{(1-\alpha \beta)\left((1+3 \beta)\left(\lambda_{x}(1-\beta)+\kappa^{2}\right)-\sqrt{\left(\lambda_{x}(1-\beta)+\kappa^{2}\right)^{2}(1-\beta)^{2}-8 \beta^{3}(1+\beta) \lambda_{x} \kappa^{2}}\right)}{2 \beta\left(\lambda_{x}(1-\beta)^{2}+\kappa^{2}\right)}, \\
g_{2}= & \frac{(1-\alpha \beta)\left((1+3 \beta)\left(\lambda_{x}(1-\beta)+\kappa^{2}\right)+\sqrt{\left(\lambda_{x}(1-\beta)+\kappa^{2}\right)^{2}(1-\beta)^{2}-8 \beta^{3}(1+\beta) \lambda_{x} \kappa^{2}}\right)}{2 \beta\left(\lambda_{x}(1-\beta)^{2}+\kappa^{2}\right)} .
\end{aligned}
$$

The numerator is thus positive provided that $g<g_{1}$ or $g>g_{2}$. In the special case that $\lambda_{x}=0$, this reduces to $q=\frac{1-\alpha \beta}{2 \beta}(1+3 \beta \pm(1-\beta))$, so that $q_{1}=2(1-\alpha \beta), q_{2}=(1-\alpha \beta)\left(\beta^{-1}+1\right)$; the numerator is again positive provided that $g<g_{1}$ or $g>g_{2}$. 